\title{
LA PUERTA DE LOS CARROS DEL MONASTERIO DE SAN PAYO DE ANTEALTARES Arquitectura, poder y urbanismo
}

\author{
Por \\ ANA MARTÍN GARCÍA

\begin{abstract}
A pesar de la falta de estudios sobre el urbanismo en Galicia, el análisis de la ciudad de Santiago proporciona una base para posibles investigaciones de las restantes en la región, que, como ella, a la sazón capital del reino, son el trazado medieval con añadidos y arreglos renacentistas y barrocos. En todas ellas, pese a su diferente origen, el urbanismo fue obra eclesiástica, ya en torno a un monasterio, convento, santuario, seminario o colegio. (Bonet Correa, A. 1984)
\end{abstract}

Antes de que el siglo XVIII llegara a su fin, Fernando de Casas y Novoa, artista fundamental del arte gallego, emprendió una obra en el Monasterio de San Payo. Corría el año 1744 cuando la comunidad de benedictinas quiso levantar un nuevo dormitorio y una entrada monumental para los carros. El lugar elegido, la zona sudeste del cenobio, hizo al arquitecto buscar con sabiduría el mejor modo de integrar el nuevo cuarto en el urbanismo compostelano, contribuyendo a enriquecer un espacio circundante a la Catedral. La cereza a este llamativo pastel la pondría Lucas Caaveiro realizando un volumétrico mirador que corona la portada.

' BONET CORREA, Antonio, La arquitectura en Galicia durante el siglo XVII, Madrid 1984, (pág. 77).

"CUADERNOS DE ESTUdiOS GALLEGOS", Tomo XLVII, Fascículo 112, Santiago 2000. 
La Puerta de los Carros ha sido arquitectónica, escultórica y estilísticamente estudiada por la profesora Folgar de la Calle en un artículo publicado por Cuadernos de Estudios Gallegos ${ }^{2}$. A este completo trabajo queremos nosotros aportarle un último matiz urbanístico, pues cuando las benedictinas deciden realizar esta obra y adelantar levemente los muros del monasterio hacia la Plaza Feijoo, lo hacen buscando unas perspectivas, buscando ser el centro de atención de una pequeña plazuela donde ya se habían reedificado varias viviendas "para mayor adorno y ornato de la ciudad"».

Dice el profesor Bonet Correa que en Galicia los arquitectos no se ocuparon de cambiar radicalmente el trazado de las ciudades, sino más bien de embellecer lo ya existente por medio de la creación de nuevos espacios ciudadanos en torno a los edificios que tenían que levantar dentro de conjuntos ya existentes ${ }^{4}$. Pues bien, en esa plaza de Feijoo y dominando desde su pétrea presencia tal ágora, nace esta Puerta de Carros, como fiel testimonio de la prestancia, del dominio, de la autoridad, de la jerarquía y sobre todo del poder que ostentaban sus moradoras. Un poder que las señoras de San Payo dejaron plasmado en las piedras que configuran esta portada conocida por el pueblo como la de la borriquita, denominación ésta que nos llevará a hablar de las devociones de estas religiosas.

En este trabajo abordaremos el nacimiento y configuración de esta zona del monasterio en sus aspectos urbanos, trataremos de lograr una visión de cómo era esa zona antes de la construcción de esta portada, qué motivó a las benedictinas a realizarla y también, porqué la obra quedó en parte inconclusa. En definitiva, nuestra investigación se centra en aportar datos novedosos que contribuyan a enriquecer, aunque sea mínimamente, el panorama urbanístico de la ciudad compostelana. No por ello olvidaremos citar a aquellas fuentes bibliográficas que han indagado y escrito sobre este monasterio, puesto que sus palabras enriquecerán y darán sentido a nuestro estudio.

\footnotetext{
${ }^{2}$ FOLGAR DE LA CALLE, $M^{\text {a }}$ del C., «La Puerta de los Carros del Convento de San Pelayo de Antealtares: Fernando de Casas y Lucas Caaveiro», en, Cuadernos de Estudios Gallegos, Tomo XXV, fasc. 100, Santiago de Compostela, 1984-85, (págs.481-499)).

${ }^{3}$ BONET CORREA, A. «La estructura urbana de Santiago de Compostela», en, Proyecto y ciudad histórica, C.O.A.G., 1976, (Pág. 35)

${ }^{4}$ BONET CORREA, Antonio, La arquitectura en Galicia durante el siglo XVII, Madrid 1984, (pág. 77).
}

"CUADERNOS DE ESTUDIOS GALlEGOS", Tomo XLVII, Fascículo 112, Santiago 2000. 


\section{EL MONASTERIO DE SAN PAYO: TIEMPO E HISTORIA}

El Monasterio de San Payo de Antealtares posee, desde tiempos medievales, una ubicación privilegiada dentro de la Ciudad Santa Compostelana, vecino a la Catedral, en el centro neurálgico de la urbe.(Plano I) Pero no fue hasta el siglo XVII cuando comenzaron a levantarse los muros del edificio que hoy observamos. Si queremos conocer cómo nació la Puerta de los Carros, cuáles fueron sus orígenes dentro del conjunto monacal, conviene que realicemos un pequeño recorrido por la historia arquitectónica y urbanística del monasterio.

Cuando en 1486 los Reyes Católicos visitaron el Reino de Galicia ${ }^{5}$, comprobaron la triste situación y la ruina en que se encontraba el Monasterio de San Martín de Fora, con una comunidad de apenas media docena de monjes que en poco seguían la observancia y el decoro de su orden. El aspecto de San Payo y de San Pedro de Fora no difería en nada ${ }^{6}$. Fue por ello que en 1487 el Papa Inocencio VIII concedía la supresión de las abadías de San Pelayo y San Pedro que perdían su autonomía y pasaban a depender de San Martín. Esta decisión no se llevaría a efecto hasta 14947. Con estas medidas iniciales podemos decir que nacía la reforma religiosa en Santiago. El objetivo era hacer desaparecer el clima de inseguridad, discordia y corrupción que vivía el monacato:

«... se fue enfriando la regular observancia, y no sólo fue abandonada por completo la antigua regla de vida, sino que sus moradores (...) llevan una existencia libre y disoluta, hasta el punto que en muchos conventos ha cesado del todo el culto divino, y sus abades, priores o comendatarios, gastan en hombres de armas sus rentas y frutos o los emplean en otros usos profanos y poco honestos, los despojan de sus tierras y haciendas, y otros bienes destinados al culto de Dios, echan fuera a los monjes y religiosos, y no cesan de cometer todos los

${ }^{5}$ Vid. GARCÍA ORO, J., La reforma de los religiosos españoles durante el reinado de los Reyes Católicos, Madrid, 1968.

${ }^{6}$ GARCÍA M. Colombás, M.B., Las señoras de San Payo. Historia de las monjas benedictinas de San Pelayo de Antealtares, Santiago de Compostela, 1980, (pág. 27).

${ }^{7}$ GARCÍA ORO, J., «La reforma de los monasterios gallegos en tiempos de los Reyes Católicos», en, Cuadernos de Estudios Gallegos, n² 21, 1966, (págs. 42-58).

"CUADERNOS DE ESTUDIOS GALLEGOS", Tomo XLVII, Fascículo 112, Santiago 2000. 
días otros muchos y nefastos atentados para perdición de sus almas, ofensa de la divina Majestad, desdoro de la religión, disminución del culto divino en dicho reino de Galicia...» ${ }^{8}$

La orden benedictina decidió que nadie podría llevar a mejor término la reforma de sus monasterios tanto masculinos como femeninos, que el prior de San Benito de Valladolid. Así se unificaron sus posesiones y se concentraron sus religiosos. Las monjas benedictinas gallegas pasaron a habitar el por entonces abandonado cenobio de San Payo, ruinoso y decadente; era julio de $1499^{9}$.

Pronto se emprenderían las proyectos para alzar un nuevo monasterio, pero el trazado del nuevo convento no se realizó de inmediato, las monjas tuvieron primero que arreglar sus asuntos económicos, asegurarse unas rentas para subsistir. De todos modos, aunque no existieran todavía contactos con arquitectos, o planos, o alzados de una nueva arquitectura, sí existían pequeños arreglos sobre los viejos $\operatorname{muros}^{10}$ y sí existía una intencionalidad de obrar, no en vano, en los últimos años del siglo XVI, las benedictinas comenzaron a ganar terreno, a mover los viejos muros medievales tratando de ganar espacio:

${ }^{8}$ LÓPEZ FERREIRO, A., Galicia en el último tercio del siglo $X V, 3^{\mathrm{a}}$ edición, Vigo, 1968, (pág. 163).

${ }^{9}$ Uno de los obstáculos más difíciles de saltar a la hora de ubicar a las religiosas en el edificio monacal de San Payo, era la donación que en 1495 hiciera Fray Juan de Melgar, abad de San Martín, a Lopo Gómez de Marzoa. Le concedían al notario de número y concejo, los claustros, huertas, oficinas, corrales y edificios de San Payo, excepto el cuerpo de la iglesia, fundando en ellos un colegio de estudiantes pobres. (Vid. JUSTO MARTÍN, M.J., «Lopo Gómez de Marzoa en el origen de la Universidad: 4 de Septiembre de 1485», en , VVAA., Gallaecia Fulget (1495-1995) Cinco siglos de Historia Universitaria, Santiago de Compostela 1995, pág. 102). Sea como fuere, antes de que el 18 de julio de 1499 se anulara el contrato establecido con Marzoa, Fray Rodrigo de Valencia, reformador de la orden por aquel entonces, había reparado y adaptado el monasterio para que en régimen de estricta clausura lo ocuparan un grupo de monjas benedictinas observantes. (Vid. GARCÍA M. COLOMBAS, M.B., Las Señoras de San Payo..., pág. 39).

${ }^{10}$ En efecto, en un primer momento las intervenciones arquitectónicas se limitaron a adecentar los viejos edificios realizando pequeños apaños para que las recién llegadas pudieran comenzar su actividad en la nueva sede. Tenemos constancia por ejemplo, de cómo el 4 de agosto de 1499, abadesa y monjas notificaban a Gonzalo de Nájera, notario del reformador, que habían gastado tanto en mantenimiento propio, como en obras y reparos del monasterio, 179.000 maravedís pares de blancas, cantidad nada despreciable. Archivo de San Payo (A.S.P.), Registro de Gonzálo de Nájera, Libro $1^{\circ}$, fol. 417 v.

"CUADERNOS DE ESTUDIOS GALLEGOS", Tomo XLVII, Fascículo 112, Santiago 2000. 


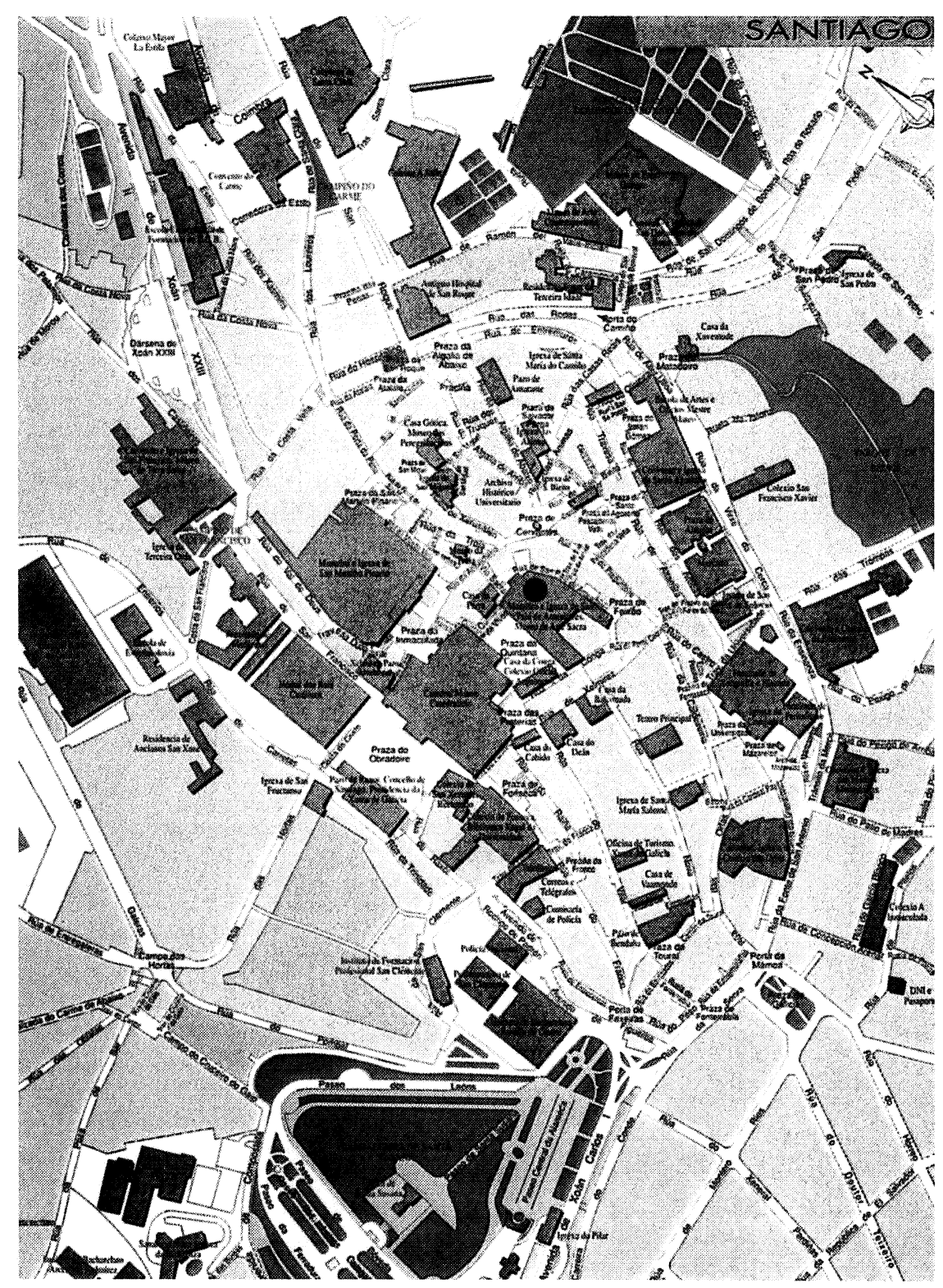

Plano I.- Plano del casco histórico de Santiago.

Resaltada la ubicación del Monasterio de San Payo. 
«...ya $V^{a}$ merced sabe, y le es notorio, que por falta de casa que tienen la abadesa, monjas y conbento del dicho monesterio, por visitas del, está ordenado que se acreciente la dicha casa y tanvien que se quiten las casas de particulares arrimadas a la de dicho monesterio ${ }^{11}$...».

En efecto, cuando las religiosas se trasladaron a aquel emplazamiento, la casa: "...estaba çercada e çerrada sobre sí e fecha un cuerpo ${ }^{12}$...».

Es importante destacar este hecho, porque que el monasterio se hallara cercado, incumbe no sólo al aspecto de la clausura, sino que al existir un muro medieval, con el paso de los años se habían venido construyendo casas adosadas a él, dificultando los proyectos de ampliación y reconstrucción del cenobio. No entraremos a detallar cual fue la evolución arquitectónica del monasterio, sino tan sólo de aquella zona que hoy ocupa la Puerta de los Carros, lugar que sufrió ciertas transformaciones a lo largo de dos siglos.

En el lugar que hoy ocupa la Puerta de los Carros desembocaba hasta 1600 una pequeña rúa llamada «de las ánimas» ${ }^{13}$. En $1576 \mathrm{el} \mathrm{monasterio}$ realizó una petición fundamental, solicitaba la inclusión de esta calleja dentro del recinto amurallado. La profesora Ana Goy Diz fue la primera en abordar el estudio de esta permuta y así lo recogió en su tesis docto$\mathrm{ral}^{14}$. De este modo el Consistorio reunido el viernes 20 de julio de aquel mismo año trató sobre:

«...lo que se pide por parte del monasterio de San Payo, en rasçón de la calle que sale de la Rúa da Conga y va a luengo del dicho monesterio a salir a la calle donde está la portería del dicho monesterio, y que está entre el dicho monesterio y la casa en que biben el

"Archivo Catedral de Santiago (A.C.S.), Varia 1a, Tomo III, Documentos antiguos 705, fol. 124.

${ }^{12}$ Archivo Histórico Universidad de Santiago (A.H.U.S.), Fondo de San Martín Pinario, Escritura de Fundación del Monasterio de Benedictinas en San Payo, Documentos sueltos, $\mathrm{n}^{\circ} 40$, fol. 4 y ss.

${ }^{13}$ La profesora Ana Goy Diz fue quien en su tesis doctoral descubrió la existencia de esa pequeña rúa. Vid. GOY DIZ, A., La arquitectura en Galicia en el paso del Renacimiento al Barroco. Santiago y su área de influencia. Santiago. Universidad de Santiago. 1995. Tesis doctoral inédita. (microfichas), (pág. 770).

${ }^{14}$ Ibid.

"CUADERNOS DE ESTUDIOS GALLEGOS", Tomo XLVII, Fascículo 112, Santiago 2000. 


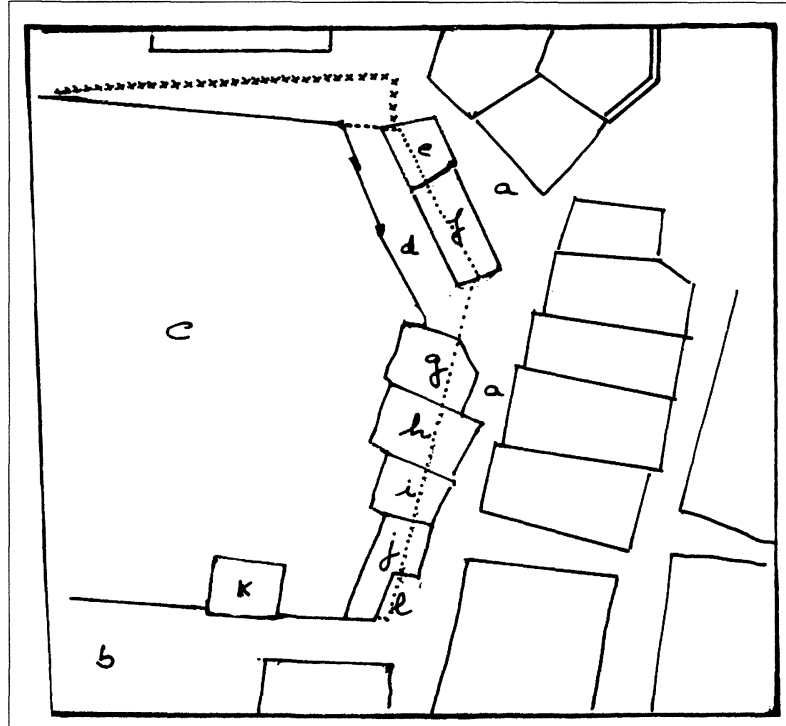

a.- Rúa da Conga

b.- Quintana.

c.- Monasterio de San Payo.

d.- Rúa das Ánimas.

e.- Casa de López Sánchez.

f.- Casa del Ldo. Ulloa.

g.- Casa del Cardenal Ruiz de Durana.

h.- Casa de Alonso Belez.

i.- Casa del doctor Juan Bibero.

j.- Casa de Gabriel Gómez. k.- Tienda y capilla del doctor Juan Biero.

1.- Esconce cedido por el arzobispo Blanco.

Indicado con línea de puntos los límites de la cerca trazada por Mateo López a principios del XVII.

Indicado con línea de cruces los límites de la Puerta de los Carros realizada en la $2^{a}$ mitad del XVIII.

Plano II.- Reconstrucción hipotética de la Rúa de la Conga. Siglo XVI.

canonigo Lopez Sanchez y el Licenciado Ulloa, que son del cabildo desta Santa Yglesia, que paresce que el dicho monesterio pide para ensancharlo ${ }^{15} \ldots \gg$.

Si observamos el Plano II entenderemos cómo era la ubicación de la pequeña rúa y cómo la de las casas que se adosaran a los muros monacales. Las benedictinas, antes de realizar esta petición, se guardaron bien de

${ }^{15}$ A.H.U.S. Libro de Consistorios VIII. (20-VII-1576), fol. 79 v.

"CUADERnOS DE ESTUdIOS GALLEGOS", Tomo XLVII, Fascículo 112, Santiago 2000. 
adquirir las casas del canónigo López Sánchez, y del Licenciado Ulloa, porque de este modo facilitaban al Consistorio la decisión, ya que la calle, a partir del momento de la compra de ambas casas, transcurría entre propiedades de las benedictinas, es decir, entre los muros de su cenobio, y las viviendas compradas. Esa era también la condición que la autoridad les imponía:

"...los dichos señores justiçia y regimiento consintiran y consienten que la dicha calle se recoxa e yncorpore en el dicho monesterio, con que primero y ante todas las cosas el dicho monesterio este entero poseedor de las dichas casas del canonigo, el Liçenciado Ulloa, y esté señalado lo que dellas y de la huerta se ha de dexar en la calle, y agan la causion y obligaçion de lo que debierede a la dicha ciudad a contento del dicho regimiento ${ }^{16} \ldots »$.

La petición de las benedictinas podría hoy causarnos sorpresa, pero la consulta de los Libros de Consistorio nos desvela que a lo largo de los siglos XVI, XVII e incluso XVIII, la ciudad de Santiago accedió a este tipo de peticiones siempre y cuando se tratase de callejas estrechas, callejones sin salida, lugares que se convertían en vertederos públicos y focos de inmundicias. De tales concesiones se aprovechaba tanto el pueblo, que por ejemplo tomaba arrendado un callejón sin salida para situar allí su tienda, como las órdenes religiosas que querían ensanchar sus edificaciones. Sin duda al Consistorio le salían más rentables estos remedios que tener que cerrar por su propia cuenta callejones peligrosos ${ }^{17}$.

\footnotetext{
${ }^{16}$ A.H.U.S. Libro de Consistorios VIII (20-VII-1576), fol. 79 v.

${ }^{17}$ Citaremos tan sólo algunos ejemplos de éstas prácticas; el 4 de julio de 1552, el Consistorio mandaba anunciar a foro ciertas callejuelas de la rúa del Campo y de la Algalia que eran focos de inmundicias. (A.H.U.S., Libro de Consistorios IV, fol. 412). El 9 de junio de 1564 «... a evitar el depósito de inmundicias en unos callejones que salian al preguntoiro y a la plaza del Campo, acuérdase aforarlos para tiendas...» (A.H.U.S., Libro de Consistorios V, fol. 226). San Martín por su parte, solicitó un callejón junto a la huerta del arzobispo (A.H.U.S., Libro de Consistorios IX, 20-VIII-1585), fol. 744). Los jesuitas también realizaron su petición, solicitaban una calleja que había entre el propio Colegio de la Compañía y unas casas situadas hacia la Calderería que con anterioridad habían adquirido para facilitar así la concesión de la vía pública. (A.H.U.S. Libro de Consistorios VIII, 6-III-1580, fol. 321 y ss).
} 
Las pelayas no cesaron en su empeño de desembarazarse de las casas adosadas a sus muros. Si retomamos de nuevo el Plano II, observamos una hipotética ubicación de cada una de las casas que hacia la rúa de la Conga, el monasterio adquirió con el fin de incorporar sus solares al recinto religioso ${ }^{18}$.

La última casa comprada a la que cronológicamente los legajos nos remiten era una casilla o tiendecita perteneciente a la capilla del canónigo Vivero, ubicada hacia la Quintana y adosada también a los muros monacales. En una carta, fechada en noviembre de 1599, en la que Fray Simón de Aguilar ${ }^{19}$ solicita que se le permita a San Payo su compra, queda patente y manifiesto como se había logrado que el edificio monacal quedara «en ysla»:

${ }^{18}$ La autorización para que San Payo tomara para sí la calleja se dictaminó el 20 de julio de 1576. Las religiosas no comenzaran a obrar hasta haber adquirido todas las casas que se adosaban a su muro a lo largo de la rúa de la Conga, esas eran las órdenes que habían recibido:

"...está ordenado que se acreciente la dicha casa y tanvien que se quiten las casas de particulares arrimadas a la de dicho monasterio por mavenientes que podian resultar...» (A.C.S., Varia 1a ${ }^{a}$, Tomo III, Documentos Antiguos 705, septiembre de 1599, fol. 124).

De este modo emprendieron la compra de todas las viviendas que se adosaran a sus muros. Al cabildo, en 11 de octubre de 1599, le compró cuatro casas vecinas al monasterio por la parte sur:

"...que son la cassa en que al presente bibe el dicho cardenal Domingo Ruyz de Durana, que linda con la calle de la Conga, y con el dicho monasterio de San Payo, y otra casa donde bibe el canonigo Alonso Belez de Guevara questa junta y pegada con la de arriba, y linda con la dicha calle de la Conga. Y otra casa en la que solia morar el dotor don Jhoan de Bibero, y linda con la dicha calle da Conga y está pegada en el dicho monasterio de San Payo. Yotra casa en que mora Gabriel Gomez pincerna desta Santa Yglessia, con su tienda que linda con la casa antecedente y con la Quintana, y con la casa del dicho monasterio de San Payo...» (A.C.S., Varia 1". Tomo III, Documentos Antiguos 705, 11 de octubre de 1599, fol. 124).

Un pequeño esconce hacia la Quintana, concedido por el arzobispo Blanco en 1577 y reafirmada la cesión por su sucesor D. Juan de San Clemente, (A.C.S., Varia $1^{\text {a }}$. Tomo III, Documentos Antiguos 705, (sin datar), fol. 178), o alguna tiendecita (A.C.S., Varia $1^{\mathrm{a}}$. Tomo III, Documentos Antiguos 705, noviembre de 1599, fol. 167), fueron las últimas adquisiciones de las benedictinas que lograron liberarse de todas las casas adheridas a sus muros por el Sur, por la Rúa de la Conga, en cuyo extremo oriental se levantará en breve un sencillo portal, antecesor de la Puerta de Carros que hoy observamos.

"CUADERNOS DE ESTUDIOS GALLEGOS", Tomo XLVII, Fascículo 112, Santiago 2000. 
«... el conbento a comprado todas las casas que estaban junto a dicho monasterio ${ }^{20} \ldots »$.

Una vez compradas las casas y otorgada la calle, había que realizar una medición sobre el terreno para estimar la línea que tomaría la rúa da Conga y el muro de San Payo, línea que hemos punteado en el Plano II. De este modo se absorbió la citada rúa de las Ánimas y se dio una configuración un tanto diferente a la rúa de la Conga, beneficiándose tanto el cenobio como el propio Consistorio, ya que el Ayuntamiento había añadido a su autorización unos condicionamientos de tipo urbanístico para la mejora de la ciudad. En la mayoría de los casos como en éste en particular, se exigía una recompensa en espacio. Las señoras de San Payo podrían absorber gran parte de la calleja de las Ánimas para ampliar su solar deshaciéndose además de las pequeñas edificaciones adosadas ${ }^{21}$, pero una pequeña parte del suelo de esas casas, pasaría a pertenecer a la ciudad que lograba así disminuir lo angosto de la rúa de la Conga. De todos modos la medida beneficiaba en mucho a las religiosas.

A partir de ese momento notamos en las benedictinas una clara intención, un proyecto, al menos mental, de edificar, tal y como lo declara la abadesa en el siguiente párrafo:

"... el dicho monesterio ha comprado unas casas grandes al cabildo desta Santa Yglessia, con sus corrales, por quantía de setemill ducados, las quales a de labrar meter y encerrar en el dicho monesterio para poder edificar dormitorio y otras celdas ${ }^{22} \ldots »$.

San Payo logra a lo largo del siglo XVI prepararse para configurarse arquitectónica y urbanísticamente hablando, como un monasterio de los tiempos modernos, a lo largo y ancho de los próximos siglos este cenobio levantará un monumental recinto cuya berroqueña presencia nos sigue

${ }^{19}$ Fray Luis de Aguilar era por aquel entonces vicario mayor de las benedictinas.

${ }^{20}$ A.C.S. Varia $1^{\mathrm{a}}$. Tomo III. Doc. Antiguos 705, (noviembre de 1599), fol. 167.

${ }^{21}$ Ese era el objetivo que perseguían pues así se lo había mandado el General de la Orden: «...que se acreciente la dicha casa y tamvien que se quiten las casas arrimadas a dicho monesterio...» (A.C.S. Varia $1^{\text {a }}$. Tomo III. Doc. Antiguos 705, fol. 124).

${ }^{22}$ A.C.S. Varia $1^{\mathrm{a}}$. Tomo III. Doc. antiguos 705 , (Es una petición sin fechar, la contestación por parte del Consistorio data del 10-IX-1599), fol. 122. 
mostrando hoy en día el poder que aquella orden benedictina y aquellas religiosas tuvieron y ejercieron.

Dentro de la evolución arquitectónica del convento se configura ese espacio que hoy ocupa la Puerta de Carros, para ella el siglo XVI creó los cimientos, para ella el siglo XVII creará el antecedente, y ella nacerá poderosa, ya en el XVIII, sobre una tradición de dos siglos.

\section{GÉNESIS DE LA PUERTA DE LOS CARROS}

Durante el siglo XVII comienzan las primeras obras mayores del monasterio de San Payo en los tiempos modernos. A pesar de que la primera mitad del XVI no tendrá arquitectónicamente hablando, tanto peso como la segunda, el Monasterio de San Payo contrata, por primera vez en ese tiempo, unas trazas con un maestro de obras de renombre, se trata de Mateo López, aquel portugués que fuera llamado por los benedictinos para trabajar en la mayor obra del tiempo; la iglesia de San Martín Pinario.

No tenemos porqué cuestionar la posibilidad de que los monjes recomendaran a las religiosas a Mateo López, a quien ellas encargan en 1600 que dicte las condiciones para la construcción de una cerca de cierre. La cerca de Mateo López fue una simple manera de poner límites al cenobio; un alto muro de mampostería con apenas complicaciones constructivas ${ }^{23}$

\footnotetext{
${ }^{23}$ La historiografía ha venido transmitiendo un error de atribución bastante destacable, nos referimos a la labor de Mateo López en el Monasterio de San Payo. Diccionarios de artistas, libros de arte, comentarios, etc, propagaron el dato de que Mateo López era el autor del lienzo mural que mira hacia la Quintana, cuando realmente su intervención arquitectónica en el cenobio fue de tono menor, tan sólo trazó una cerca de cierre. Pérez Costanti no miente cuando en su Diccionario de artistas atribuye a Mateo López las condiciones de una obra que por 1330 ducados toman los maestros canteros Melchor López y Gaspar de Arce el «mozo», pues así es y en breve analizaremos documentos que lo afirman. El dato que ha llevado al equívoco es el tipo de obra que Costanti cree que se construyó, dice:

«...en 1600 dictó las condiciones para la construcción de las grandes paredes externas del monasterio de San Payo de Santiago...» (Vid. PÉREZ COSTANTI, P. Diccionario de los artistas que florecieron en Galicia durante los siglos XVI-XVII, Santiago 1930, pág. 337).

En base a ello Bonet Correa relaciona al cantero luso como el autor del gran lienzo mural de la Quintana, es decir con el Cuarto Nuevo que realmente trazó Bartolomé Fernández Lechuga y levantó Jacome Fernández allá por la década del 40.
}

"CUADERnOS DE ESTUdIOS GALLEGOS", Tomo XLVII, Fascículo 112, Santiago 2000. 
que se extendía desde la zona oeste del monasterio, es decir, desde la Quintana (aproximadamente desde el medio del lienzo mural que hoy observamos), doblando hacia el sur por la Rúa de la Conga, y doblando nuevamente hacia el este por el lugar que hoy ocupa la Puerta de Carros $^{24}$.

La regla benedictina establecía ya unas condiciones de cómo debía ser ese muro que se iba a levantar:

«...que las cercas de los monasterios e de la huertas dellas sean altas e rezias e sin ningun agujero ${ }^{25} \ldots »$.

Formalmente se trata de una cerca de mampostería con los esquinales de sillería, de una altura considerable y con una bien pensada cimentación. Las condiciones las realiza Mateo López, la obra la ejecutan Melchor López, Juan Díaz, Baltasar Fernández, Baltasar González, y Gaspar de Arce el mozo. Como fiador aparece Gaspar de Arce el viejo ${ }^{26}$.

Lo que el luso elabora es solamente un diseño de una cerca de cierre lisa y elevada que es más, apenas sí mira hacia la Quintana, centrándose más en la zona sur, la que mira hacia la Conga. Lechuga es el genuino trazista de ese lienzo nuevo que Bonet relaciona estilísticamente por su belleza geométrica tan de nuestro tiempo, con Gropius o Le Corbusier y que bien poco tiene que ver con el sentido ornatista de Mateo López.

A partir de estos dos estudios el error se propagó y Mateo López aparece citado en mil y una fuentes bibliográficas como el autor del lienzo mural.

Ana Goy Diz sí se percató de este fallo y así lo plasmó en su tesis doctoral (GOY DIZ, A., La arquitectura en Galicia en el paso del Renacimiento al Barroco, Santiago y su área de influencia. Santiago. Universidad de Santiago. 1995. Tesis doctoral inédita. (microfichas), pág. 770-777).

${ }^{24}$ Vid. A.H.U.S. Fondos Municipales. Libro de Varia. Tomo IV. Artistas (1522-1753), Condiçiones, postura y remate de la obra de San Payo, (fol. 537-538).

${ }^{25}$ Constituciones de los monges de la Congregacion de San Benito de Valladolid. En Barcelona. En Casa de Pedro Malo impresor de libros, Año de MDLXXV, Capítulo LXXXXV, «De las obras en los monasterios», (pág. 151). (Ejemplar consultado en el A.S.P.)

${ }^{26}$ Las obras se iniciaron en el 1600 , sin embargo debieron de verse paralizadas porque en 1603 se estableció un nuevo contrato para terminar la obra «...que falta por hazer hacia la Quintana...» (Instituto Padre Sarmiento I.P.S., Documentos sueltos, fol. 715). De todos modos a nuestro estudio nada afecta este nuevo contrato ni las pequeñas obras de construcción de celdas que también se realizan en esta primera mitad del XVII.

"CUADERNOS DE ESTUdIOS GALLEGOS", Tomo XLVII, Fascículo 112, Santiago 2000. 
Conviene hacer notar esa primera preocupación por dar una homogeneidad exterior al monasterio, tratando de igualar en una misma línea sus muros, ahora que ya no existen edificaciones adosadas a las paredes ${ }^{27}$.

En la rúa de la Conga el muro se realizaría en varios tramos, debido a la pendiente de la calle que les lleva a cuidar extremadamente la cimentación levantando diferentes taludes. La casa del Licenciado Ulloa era el punto medio del primer tramo de la Rúa de la Conga antes de que se produzca su giro y se encamine hacia la Plaza de Feijoo. (Plano II ). La tapia hacia la calle de la Conga estará marcada por un ángulo que todavía hoy perdura. A pesar de la existencia de ese giro, había también aquí una preocupación por lograr una uniformidad, por obtener un cierre que hacia todos sus frentes denotase un único dueño. Veamos como se configuró esta parte del muro.

Para facilitar una buena cimentación sobre una zona en desnivel dividen el muro que uniría la esquina de la Quintana con la parte más elevada del convento, ya en la rúa de Tras San Payo, en tres pedazos de unos 20 palmos de longitud cada uno. Las tres partes serían iguales en sus medidas sólo que cada una se levantaría sobre su propio talud, su propio escalón de base, sin embargo en el aspecto final no se mostrarían como tres muros, sería uno único rematado en su cima por una hilera de sillería.

El grosor del muro variaba a medida que éste se erguía; en su base era de cuatro pies y medio, en su punto medio era de tres pies y desde allí hasta su punto más alto, aquel que alcanzaba los treinta pies con respecto al suelo, era de dos pies y medio. Tal diferencia de anchura propiciaba una buena estabilidad de la pared.

Esta reiterada uniformidad en los muros se rompía solamente hacia el este, pues hacia allí se abrió una pequeña portada:

«...y a de haber en esta pared, en la parte donde le fuer señalada una puerta muy bien enecha de pedra de grano, bien labrada y hescodada ${ }^{28}$ con sus pilares por de fuera, y una cornixa muy bien echa,

${ }^{27}$ Cuando en 1641 Jacome Fernández tome la obra del Cuarto Nuevo trazado por Bartolomé Fernández Lechuga, la importancia de este límite externo será considerable, porque será la que marque la línea sobre la que tanto en la Quintana como en la Rúa Conga, se levantará la cimentación de los nuevos muros del famoso lienzo de San Payo.

${ }_{28}$ «hescodada», viene de «escodar», es decir, labrar las piedras con martillo. 
que a de serbir de portería y será del anchor y altor que le señalaren $^{29} \ldots »$.

El texto dice que la puerta se abrirá en un punto concreto que se señalará oportunamente a los maestros, lo que nos parece indicar que no debía de existir en aquel lugar un acceso, no debía haber abertura alguna hacia esa zona en donde a partir de ese momento, encontraba su nacimiento la rúa da Conga. Cuando el documento nos habla de «portería» no debemos pensar en un cuarto cerrado, sino tan sólo en una entrada del recinto monacal que daría paso a su patio o huerta. Digamos pues, que esta puerta fue la antecesora a la Puerta de los Carros que hoy conocemos.

Las Constituciones de los Monges de San Benito de Valladolid, versan sobre algunos aspectos que guardan relación con la forma que tendría la puerta que ahora nacía en este monasterio femenino:

"...si hubiere de haber puerta para el servicio de la huerta, que la tal puerta tenga dos cerraduras la una por la parte de fuera e la otra por la parte de dentro, con guardas e llaves diferentes e la llave de la cerradura de fuera la tenga el mayordomo del monasterio, y la llave de la cerradura de dentro la tenga la abbadesa para que no pueda entrar nadie sin que la abbadessa lo sepa ${ }^{30} \ldots »$.

La nueva puerta respondía a la necesidad funcional de un acceso para los carros a la huerta. Nuevo acceso que, como acabamos de leer, debería de estar vigilado. En este caso en particular las benedictinas cumplen con la norma y además denotan ya una intención de dejar patente su presencia, flanquean la puerta con unos pilares que sostienen un dintel marcado por una saliente cornisa. A pesar de la humildad de este proyecto merece la pena su mención.

\footnotetext{
${ }^{29}$ A.H.U.S. Fondos Municipales. Libro de Varia. Tomo IV. Artistas (1522-1753), fol. 538.

${ }^{30}$ Constituciones de los monges de la Congregacion de San Benito de Valladolid. En Barcelona. En Casa de Pedro Malo impresor de libros, Año de MDLXXV, Capítulo LXXXXV, «De las obras en los monasterios», (pág. 151). (Ejemplar consultado en el A.S.P.)
}

"CUADERNOS DE ESTUDIOS GALLEGOS", Tomo XLVII, Fascículo 112, Santiago 2000. 
El siglo XVII continuó con una gran actividad constructiva en el monasterio, las benedictinas levantaron en la primera mitad de esa centuria el lienzo mural de la Quintana, sus habitaciones, refectorio, parte del claustro, cocinas, etc., haciendo realidad las trazas efectuadas por Bartolomé Fernández Lechuga.

En la segunda mitad del siglo, el protagonista fue Melchor de Velasco, continuador en parte de la obra de Lechuga y creador de nuevas habitaciones, locutorios, y de una puerta monumental en el muro este, la que conocemos como Portería de San Payo. Los nombres de estos arquitectos a los que sumamos el ya mentado Mateo López, son fiel testimonio de la fortaleza de esta orden benedictina que ya en sus Constituciones establecía que las obras tenían que ser encomendadas a artistas de primera fila:

"...Quando el Reverendísimo diere licencia para començar alguna obra, mande en la misma licencia que primero se haga la planta y la traza por un Maestro Architecto que sea bien instruido en la arte, y que no se de a tassacion sino a destajo, poniendo primero cedulas en partes donde pueda aver Maestros y Oficiales que puedan tomar la obra, y señalando dia de remate, para que se de al que mejor, más barato, y con mejores fianzas las hiziere: y que en la escritura se concierten las mejoras que se alteraren de la traza ${ }^{31} \ldots \gg$.

A pesar de que el «Seicento» llegó a su fin para las benedictinas con grandes pesares y pérdidas sobre sus espaldas; obras, un incendio, precariedad económica... lo cierto es que en el XVIII se recuperaron y afectadas por lo que Colombás dio en llamar «mal de la piedra» ${ }^{32}$ realizaron dos nuevos proyectos: el levantamiento de una nueva iglesia y su último «cuarto nuevo», el que va desde la Portería a la Puerta de los Carros.

\footnotetext{
${ }^{31}$ Constituciones de la Congregación de Nuestro Glorioso Padre San Benito de España e Inglaterra. Augmentadas y añadidas con las nuevas difiniciones que desde el año 1610 hasta el 1701 han sido establecidas y aprobadas en diversos capítulos (...), Impresas en Madrid a costa de la Congregación, en la oficina de la Viuda de Melchor Álvarez, año de 1706. (Consultado en el A.S.P.), capítulo 26, «Obras de los monasterios», pág. 243.
}

${ }^{32}$ GARCÍA M. COLOMBÁS, M.B., Las señoras de San Payo..., (pág. 278).

"CUADERNOS DE ESTUDIOS GALLEGOS", Tomo XLVII, Fascículo 112, Santiago 2000. 


\section{LA CONSTRUCCIÓN DEL ÚLTIMO «CUARTO NUEVO»}

En efecto, la precariedad de la segunda mitad del XVII se olvidó en el XVIII, cuando ya en su primera mitad contaron las religiosas con un superávit tal que les permitió, tras levantar e inaugurar de forma solemne la nueva iglesia en 1707, asumir una nueva gran obra que afectaría a aquella zona donde a principios del XVII se había levantado una simple portada pétrea $^{33}$.

La función de aquella tosca puerta era la de dar entrada a los carros al convento, era el acceso a la zona de huerta, la zona donde se ubicaban los almacenes de grano, de vino, etc. Ya antes del levantamiento de la nueva portada, la vieja era conocida como Puerta de los Carros. Así lo comprobamos por ejemplo en el listado de obras llevadas a cabo durante el abadiato de $\mathrm{D}^{\mathrm{a}}$ María de Noboa y Sarmiento, datado entre 1709 y 1713 , cuando:

«...se hizo una calzada de cantería pegada a este monasterio, que principia desde la portería principal hasta la puerta de los carros; se hizo nueva de madera la puerta de los carros ${ }^{34} \ldots »$.

\footnotetext{
${ }^{33}$ Las Constituciones de la Orden no permitían que se diera comienzo a obra alguna en tanto existieran deudas que pagar:

«...mandamos a los abades pena de suspension de un año que no comiençen obra principal, como Iglesia, Sacristía, Rexa, Retablo, quarto de Casa o otra obra desta calidad, en quanto la casa debiere censos, hasta que se desempeñe, sino fuere con licencia del Reverendísimo general, y su Reverendísima no la dé, si huviere el dicho empeño, o otra obra principal comenzada...»

Vid. Constituciones de la Congregación de Nuestro Glorioso Padre San Benito de España e Inglaterra. Augmentadas y añadidas con las nuevas difiniciones que desde el año 1610 hasta el 1701 han sido establecidas y aprobadas en diversos capitulos (...), Impresas en Madrid a costa de la Congregación, en la oficina de la Viuda de Melchor Álvarez, año de 1706. (Consultado en el A.S.P.), capítulo 26, «Obras de los monasterios», pág. 243.

${ }^{34}$ BUJÁN, Sor Mercedes, Abadalogio Femenino del Monasterio de benedictinas de San Pelayo en Santiago de Compostela, obra inédita, (págs. 81 y 82). (Nuestro agradecimiento a Sor Mercedes Buján, archivera del Monasterio de San Payo por su paciencia, por todas sus atenciones y por el trato familiar que concede a todos los que requerimos su ayuda).
}

"CUADERNOS DE ESTUdIOS GALLEGOS", Tomo XLVII, Fascículo 112, Santiago 2000. 
Unos años antes de llevarse a efecto la obra de las nuevas habitaciones por Fernando de Casas y Lucas Ferro Caaveiro ${ }^{35}$, se realizará un pequeño arreglo sobre aquella zona que nos desvela, al menos superficialmente, como era aquel lugar hasta mediados del XVIII:

«...se hizo un alpendre con sus puertas para la portería de los carros y una galería para pasedizo desde el monasterio a dicha puerta $^{36} \ldots »$.

Es decir, se realizó una construcción cubierta donde se albergarían y recogerían los carros, o al menos esa es la definición de alpendre. Además para lograr un fácil tránsito entre lo que el documento llama «el monasterio», refiriéndose al edificio monacal y la Puerta de los Carros, separado lo uno de lo otro por unos cien metros, se construyó un tejadillo, un pasillo cubierto que seguramente iría adosado, por la parte interna, al muro de cierre del recinto.

Desconocemos en qué momento se tomó la decisión de realizar la gran obra nueva, ni qué motivó esta decisión de ampliar nuevamente el edificio. Podríamos pensar que se produjo un incremento en el número de religiosas, lo cual haría necesario la construcción de nuevas habitaciones, pero realmente las benedictinas con el paso de los años fueron disminu-

\footnotetext{
${ }^{35}$ Folgar de la Calle («La Puerta de los Carros del ... págs. 491-494) es quien atribuye esta obra a ambos arquitectos. Los libros de Depósito en ningún momento citan maestro de obras, ni proyectista, ni tampoco dicen quien dirigía la obra. Sin embargo el lenguaje arquitectónico utilizado (enmarcar la portada con pilastras, el cajeado rehundido de las pilastras...) nos habla de Fernando de Casas, y es más, nos habla de su estilo final, más próximo al Rococó que al modo de hacer aprendido de su maestro Domingo de Andrade. Nada hay en esta portada de decoración vegetal, y mucho de compleja molduración.

La intervención del otro arquitecto se deja notar en el mirador. Lucas Ferro Caaveiro ya había concluido con anterioridad obras de Casas, por lo que para nada resulta descabellada la propuesta de Folgar de que en este caso sea también él quien tome las riendas de la obra hacia 1750. En 1749 el mirador aún no se realizara, y ese mismo año fallecía Fernando de Casas. Lucas Caaveiro debió de tomar la obra, y él mismo debió de ser quien diseñara y elaborara ese mirador. Apunta la profesora Folgar cómo el peculiar uso de los balaustres llegó a Galicia muy tardíamente, dato que nos acerca nuevamente a Caaveiro como su autor.

${ }^{36}$ Ibid. (pág. 92). Estas obras se llevaron a cabo bajo el abadiato de $\mathrm{D}^{\mathrm{a}}$ Antonia Nicolasa Giráldez y Caamaño comprendido entre 1737 y 1741.
} 
yendo en número, de tal manera que si durante el siglo XVII podríamos establecer una media de entre 60 y 65 monjas, para el XVIII la encontramos de $50^{37}$. Ni ese número era el del total de personas que habitaban en el monasterio, ni el descenso de religiosas se debe a una falta de vocaciones. Lo primero porque en San Payo, al lado de muchas de las religiosas vivía su criada, es bien cierto que la regla mandaba lo contrario, pero también lo es que en el cenobio habitaban auténticas señoras de alta cuna acostumbradas a un modo de vida más señorial que benedictino de estricta clausura. Tampoco nos centraremos en pensar en el descenso de número de vocaciones, dado que muchas veces era la carestía de los tiempos o las bajas en las rentas que percibía el monasterio lo que llevaba a tomar medidas como:

«...porque al presente se halla este Real convento con excesivo número de religiosas con grandísima baja de sus rentas y casi imposibilitado de sustentarse y acudir a gastos precisos y pleitos inexcusables para conservar y cobrar las que han quedado, mandamos que por este cuatrienio no se den más hábitos ${ }^{38} \ldots »$.

La razón del porqué de esta nueva fábrica nos es entonces desconocida y quizás sólo explicable, dentro de esa «enfermedad» constructiva que hizo a las benedictinas no abandonar jamás las obras en el convento.

Tenemos constancia de la petición donde la abadesa de San Payo solicita la licencia de obras al Ayuntamiento:

«Señores Justicia y Regimiento de esta ciudad:

La abadesa y demás relixiosas de este monasterio de San Payo, representan a $V$. $S^{a}$. como por la estrechez de dicho monesterio se ven

\footnotetext{
${ }^{37}$ Exactamente de 1657 a 1665 eran 67 las monjas que habitaban en San Payo, de 1665 a 1669 eran 68, de 1669 a 1673 eran 63, ya más próximos al siglo XVIII, de 1697 a 1701 había 62 monjas y tres novicias, de 1701 a 1705 un total de 64 , y a partir de ese momento comienza a bajar el número, de 1706 a 1713 tenemos 59, de 1717 a 1721 hay 58, del 1733 al 1737 tan sólo 54, y ya lleganido a la mitad del siglo, de 1745 a 1749 bajamos a 52 , y a 48 de 1762 a 1765 .

${ }^{38}$ BUJÁN, Sor Mercedes, Abadalogio Femenino del Monasterio de benedictinas de San Pelayo en Santiago de Compostela, obra inédita, pág. 58
} 
precisas a hechar y hacer un nuevo quarto dormitorio desde donde termina la Vicaría asta la Puerta de los Carros, y reconocido por los maestros de obras, hallan por esencialmente necesario para salir a nivel, coger alguna porción de la calzada que está contigua a la cerca y que el esquinal último azia la plazuela de Feijoo salga en poca distancia a la calle.

Y siendo cierto no se perjudica en cosa al público que sea notables, suplican a V. Sa. Se sirva dar su permiso y consentimiento, para poder fabricar dicho quarto con la extensión expresada...

\section{Juana Antonia Herce}

Abadesa» ${ }^{39}$

Las religiosas sabían y conocían cómo era el nuevo cuarto que querían levantar, (Plano III) y tal y como se expresa en la petición anterior, necesitaban tomar unas cuartas a la calle con el fin de que las nuevas paredes siguieran la misma línea que las que antaño erigiera Melchor de Velasco. El objetivo de este petición era lograr que las dos puertas del convento, la de la Portería y la de los Carros, guardasen la misma línea. Lo que lograrían era sin embargo muchísimo más, una mayor presencia urbana, una ostentación y una nueva muestra del poder benedictino.

El 22 deAgosto de 1744 se presenta en el Ayuntamiento el informe del arquitecto encargado de reconocer la petición cuyo contenido fue el que sigue:

«...en cumplimiento de lo mandado por $V . S^{a}$. en ayuntamiento de 8 del corriente, hemos reconozido el sitio que pide el monasterio de San Paio para la fábrica de un nuevo quarto, y aviéndonos acompañado del maestro de obras Fernando de Casas y éste tirado las líneas y medidas según arte, allamos que desde la esquina de la vicaría de dicho monasterio, debe seguir una pared asta cerca la Puerta de los Carros que mira a la Plaza de Feijoo, la qual dicha pared llega abriendo en aumentazión, asta la cantidad de tres varas menos quarta, y son las que por aquella parte necesita dicho monasterio, quedando la calle de cinco varas y terzia por la parte más angosta como todo ello se

${ }^{39}$ A.H.U.S. Libro de Consistorios, $\mathrm{n}^{\circ} 164$, fol. 408. (VIII-1744)

"CUADERNOS DE ESTUDIOS GALLEGOS", Tomo XLVII, Fascículo 112, Santiago 2000. 
demuestra mas vien por el diseño que acompaña, en cuia atención, no consideramos ningún perjuício a la calle pública ni a la servidumbre de los vezinos que la biven ${ }^{40} \ldots$..

Acompañando a este informe aparece recogido en el Libro de Consistorios ese pequeño plano que elaboró Fernando de Casas donde se especifica con exactitud el trazado de la nueva línea, y donde nosotros además podemos conocer cómo era la antigua. (Plano IV)

La autoridad consideró aceptable la petición, eso sí bajo unas condiciones:

"-Que para abrir y cimentar la dicha obra aian de avisar prezisamente a dichos tres señores para que se allen presentes.

-Que no an de estorbar ni empidir en ningún tiempo a los vezinos, dueños y avitadores de las casas de aquella circunferencia, el que puedan reedificarlas y levantarlas con puertas y ventanas a la calle pública.

- Y que aia de ser de cargo de dicho monesterio el azer y reedificar la calzada que va desde la Vicaría, arededor de la guerta asta zerrar con el caño de agua que sale de dicho monasterio al riego de agua, componiendo éste. Con la advertencia de que desde la Puerta de los Carros asta dicho caño, solo se entienda la media calle ${ }^{41} \ldots »$.

El primero de los puntos se refiere a Rodrigo Antonio Falcón, Bernardo de Millara y Mathias Moscoso y Romani, los cuales habían sido los encargados de realizar el informe y de acompañar a Fernando de Casas en su evaluación de la solicitud; serían ahora por tanto, los encargados de observar que la obra se llevara a cabo siguiendo la línea fijada y los términos establecidos.

${ }^{40}$ A.H.U.S. Libro de Consistorios, ${ }^{\circ} 164$, fol. 409. (22-VIII-1744)

Vid. FOLGAR DE LA CALLE, $M^{a}$ del C., «La Puerta de los Carros del Convento de San Pelayo de Antealtares: Fernando de Casas y Lucas Caaveiro», en, Cuadernos de Estudios Gallegos, Tomo XXV, fasc. 100, Santiago de Compostela, 1984-85, (págs.482).

${ }^{41}$ A.H.U.S. Libro de Consistorios, $\mathrm{n}^{\circ} 164$, fol. 421. ( $\sin$ fechar).

Vid. FOLGAR DE LA CALLE, $M^{\mathrm{a}}$ del C., «La Puerta de los Carros...» (págs.481y 82).

"CUADERNOS DE ESTUDIOS GALLEGOS", Tomo XLVII, Fascículo 112, Santiago 2000. 


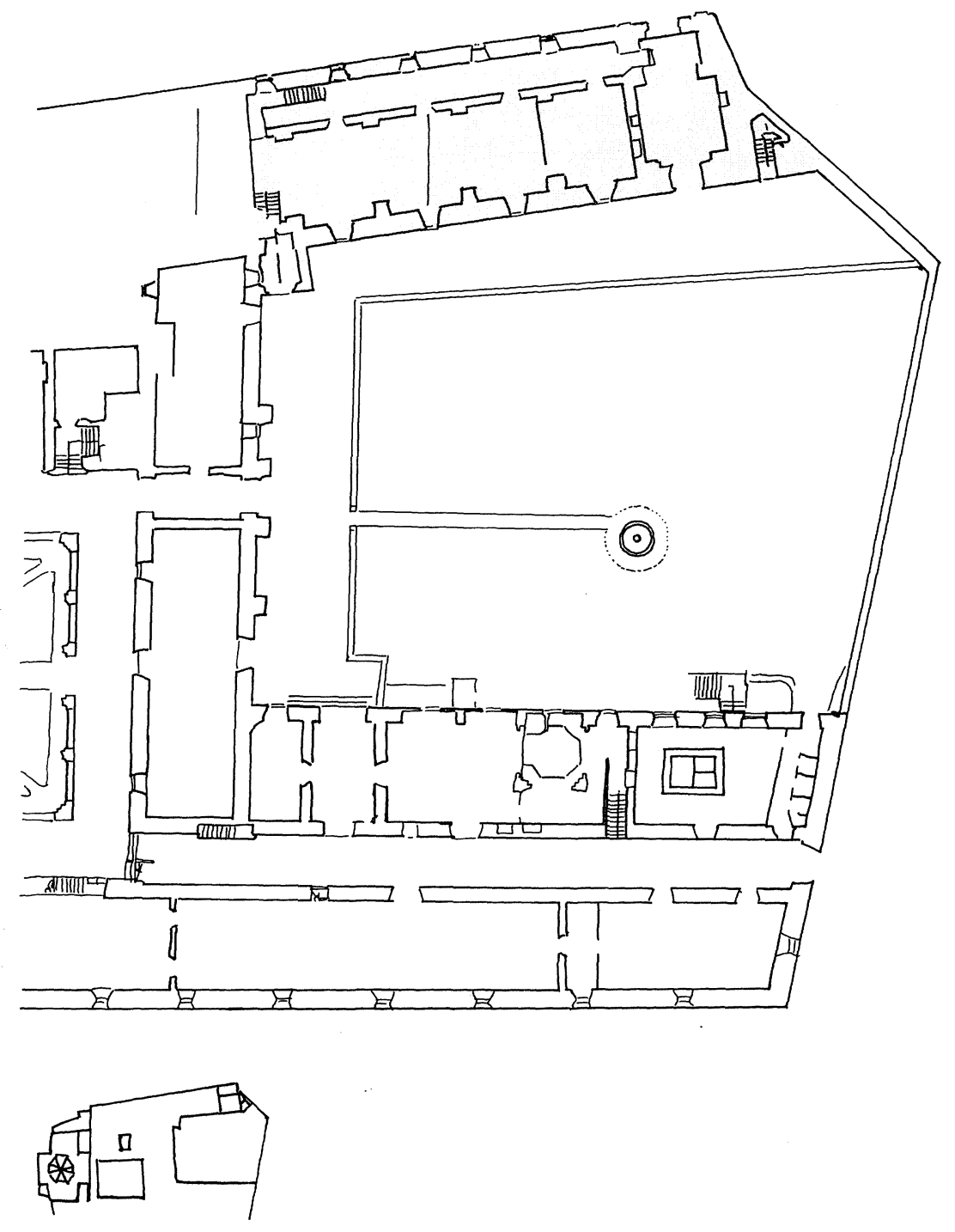

Plano III.- El Cuarto Nuevo de Fernando de Casas. 


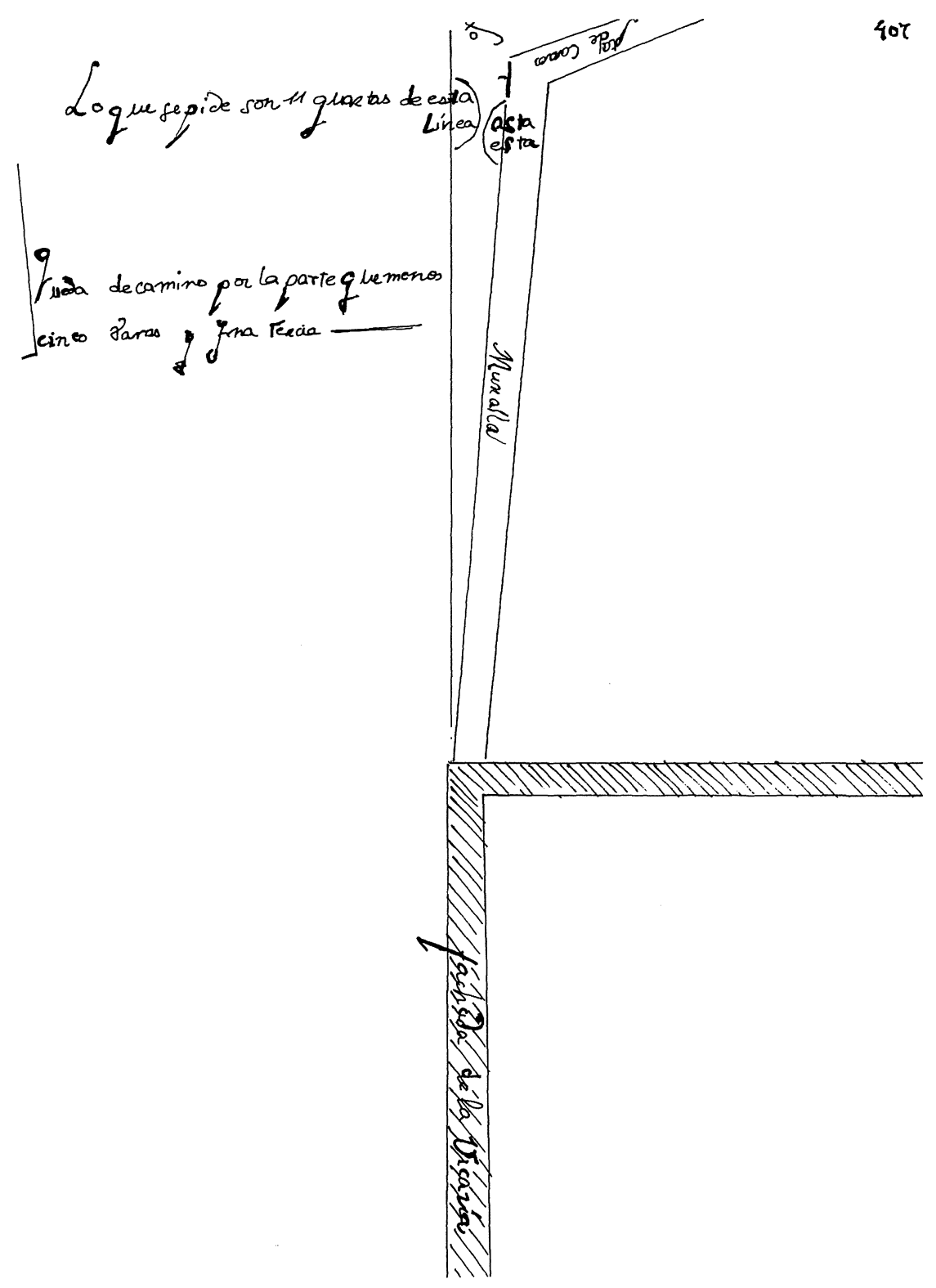

Plano IV.- Plano que acompañaba a la solicitud autorización para la ampliación del monasterio. 
Con respecto al segundo punto no nos debe de causar extrañeza tal exigencia puesto que a la hora de erigir una edificación vecina a un monasterio o convento, éste vigilaba que desde ningún lugar del nuevo inmueble se pudiera divisar su intimidad, sus habitaciones o huerta, en suma, su clausura. San Payo ejerció este «poder» sabedor de que la legislación favorecía a las comunidades religiosas ${ }^{42}$. Podríamos citar varios ejemplos de pleitos que las benedictinas interpusieron contra alguno de sus vecinos que trataba de levantar una nueva edificación, o bien dar mayor altura a su vivienda perjudicando, según entendían las religiosas, su recogimiento. Así sucedió con unas casas en la Quintana de Palacios desde las que se divisaba el coro alto de la iglesia, así sucedió con casas vecinas a la vicaría y así, en viviendas que se levantaban en Fuente Sequelo y que divisaban la huerta de las monjas ${ }^{43}$.

Pero sin duda el caso que más nos interesa por su ubicación en la plaza de Feijoo, vecina a la Puerta de Carros, es el de la vivienda que el canónigo Don Juan Antonio Somoza trataba de fabricar allí. La casa antigua tenía dos alturas, pero en el momento de la demanda, la nueva vivienda alcanzaba en un solo piso, la altura que tendrían los dos que antes existían:

«...Don Juan Antonio Somoza estaba fabricando de cantería una casa que tiene suia sita en la Plazuela que se dice de Feijoo de esta ciudad, que hace frente a ella y cercana a la Puerta de los Carros (...) que antes era la mayor parte de pizarra y de dos altos: con su balconada de cantería a dicha plazuela.

Y porque la tiene echa de dicha cantería y solo de un alto, alcanza los dos altos que thenía (...)

Y pretendiendo hacerle otro alto con sus ventanas, maineles y solana también de cantería, y rezelosa dicha Abbadesa y convento de que desde dichas ventanas y solana se había de registrar la mayor parte de las zeldas, solanas y salido deste dicho convento, habian (...) puesto sequestro por los noventa días de la ley en dicha obra ${ }^{44} \ldots$..

${ }^{42}$ Vid. MARTÍN GONZÁLEZ, J.J., «Algunas peculiaridades del urbanismo español», en Homenaje a Hernández Díaz, T.I, Sevilla, 1982, (págs. 466 y ss.), citado por FOLGAR DE LA CALLE, $M^{\text {a }}$ del C., «La Puerta de los Carros...» (pág. 482)

${ }^{43}$ Datos frutos de un estudio personal que esperamos sacar pronto a la luz.

${ }^{44}$ A.H.U.S. Notario Pedro Vázquez, Protocolo ${ }^{\circ}{ }^{\circ} 1994$, Concordia entre el Convento de San Payo y el Canonigo Don Juan Antonio Somoza, (fols. 94-95).

"CUADERNOS DE ESTUDIOS GALLEGOS", Tomo XLVII, Fascículo 112, Santiago 2000. 
La solución al embargo de la obra vino de la mano de Domingo de Andrade que realizó petición de ambas partes un peritaje y determinó:

«...digo debajo de mi conciencia (...) que dicho sr. Canónigo Don Juan de Somossa, por quanto antes tenía registro a algunas partes de dicho conbento como son algunas ventanas y no veia lo interior de las celdas por estar dicha su casa a un lado de dicho conbento y no hacer frente a el como hacen otras casas de algunos vecinos; sino que hace frente a dicha plazuela de Feyxo, y por su testero, o delantero hace frente a dicha calle.

Digo que Don Juan de Somossa puede suvir su casa, ygual de las otras de buena fábrica que ay en dicha plazuela, las cuales están enffrente de dicho conbento, por el adorno y ornamento de la ciudad ${ }^{45} \gg$.

Se le prohibía a Somoza abrir ventanas hacia el monasterio, y aún es más, aquellas que abriera a partir de una determinada altura deberían ser fijas, al igual que el balcón de la fachada principal que podría realizarse pero que se cerraría con celosías:

«...Y para que no registren tanto a dicho conbento la ventana que caie a dicha fachada azia la esquina no la aga y solamente aga encima della una vidriera en el maynel para dar luz a aquella parte de la casa; y asimesmo no aga ventana en dicho segundo alto en la trasera que hace frente a dicho conbento (...) y que en dicha fachada de dicho segundo alto no aga balcón ni corredor azia dicha plazuela y que en las ventanas ponga zelosías y en las vidrieras y mayneles dellas ponga redillas de alambre.

$Y$ en la ventana del medio de dicha fachada que caie a dicha plazuela, la aga puerta balcón con su rexa de balustres y su celosía, lo uno para adorno de dicha fachada, lo otro para ventilar su casa...

${ }^{45}$ A.C.S. Varia $1^{\text {a }}$, Serie, Tomo III, Documentos antiguos 705, Concordia entre el monasterio de San Payo y el canónigo Don Juan Antonio Somoza sobre la fábrica de una casa en la plazuela de Feijoo, año 1707, (fol. 50).

"CUADERNOS DE ESTUDIOS GALLEGOS", Tomo XLVII, Fascículo 112, Santiago 2000. 
...privo a que nadie se pueda asomar a los mayneles y vidrieras ni que aga corredor o solana en dicho segundo alto ${ }^{46} \ldots »$.

Lo firmaron y acordaron ambas partes, sin embargo el canónigo no cumplió su parte con lo que al menos hasta 1709 continuaron los pleitos. Nos interesa el contenido de la concordia que acabamos de transcribir porque en cierto modo nos narra cómo se iba transformando la Plaza Feijoo. Las viejas casas de pizarra fueran sustituidas por casas de cantería:

«...estaba de mala calidad y que se arruinaba en partes por ser de piedra pizarra las paredes que caiyan a dicha plazuela, y su fachada que caie a la calle que va de dicha plazuela a la Calderería ser de tabiques ${ }^{47} \ldots »$.

Y existe una preocupación por crear una plaza hermosa, por configurar un conjunto armonioso, donde todas las viviendas guardaran normas de decoro, contribuyendo así al ornato de la ciudad. Esa plaza comienza a gozar de una estética y es dentro de este cambio donde cobra sentido que las benedictinas transformen un simple acceso al recinto en una puerta monumental que aspira a convertirse en el punto de mira de la explanada. La Plaza de Feijoo continuaba siendo un lugar de tránsito muy concurrido, un lugar no sólo tanto de ocio sino más bien para el negocio. Sin ir más lejos todavía en 1759, y hablamos de una fecha en la que ya se ha concluido la obra de la Puerta de los Carros, en la plazuela se realizaba la venta de yerba. Ante el peligro que la actividad suponía el Ayuntamiento tomó las siguientes medidas:

"...que los hazes de paja y de hierba que diariamente se venden en esta dicha ciudad que ocupaban el paso en la plazuela de Feixó por donde bienen todas las procesiones públicas del Corpus Christi y otras que salen de la Santa Yglesia, y vienen todos los transitantes, maior

${ }^{46}$ A.C.S. Varia $1^{\text {a }}$, Serie, Tomo III, Documentos antiguos 705 , (fol. 50 v.) y A.H.U.S. Notario Pedro Vázquez, Protocolo ${ }^{\circ} 1994$, Concordia entre el convento de San Payo y el canonigo Don Juan Antonio Somoza, (6-IX-1707), fol. 94-95.

${ }^{47}$ A.C.S. Varia $1^{\mathrm{a}}$, Serie, Tomo III, Documentos antiguos 705, (fol. 50). 
parte desde las calles principales de la Rua del Villar, Rua Nueva, y otras a la Plaza Pública, carnicería, pescadería, y a vever a la fuente de dicha plaza, todas las cavallerías del lugar.

$Y$ del propio modo bajan todos por dicho sitio que no es capaz de sufrir lo que ocupa con dicha hierva y paja, causando graves inconbenientes, y aun a peligro a subceder muertes con tanta cobcurrencia de cavallerías, carros cargados y concurso de gentes.

Por lo cual y para evitarlo hemos dispuesto pasase a venderse dicha paja y hierva a la plazuela nombrada del mercado ${ }^{48} . . . »$.

Retomemos el tema de nuestra investigación, cuando en 1748 se firmó y confirmó la autorización para llevar adelante la obra ${ }^{49}$, lo cierto es que las religiosas ya habían comenzado la fábrica. La actividad constructiva se adelantó a ese permiso, de este modo tenemos noticia de cómo bajo el abadiato de $\mathrm{D}^{\mathrm{a}}$ Juana Antonia Herce, comprendido entre 1741 y 1745:

«...se empezó la pared interior que ha de servir al Cuarto Nuevo, que mandó tirar el abad general hasta la Portería de los carros, y quedan en ella hechas los arcos que han de servir para bóveda de la granería. Se dispuso en nueva forma todo el cuarto que sirve de fachada a la vicaría, asi en el interior como en el exterior del monasterio, de suerte que, a excepción de tres paredes maestras, todo se hizo nuevo ${ }^{50} \ldots »$.

Si las obras se iniciaron era porque la economía del monasterio debía permitirlo y en efecto, desde al menos 1737 los libros de cuentas de San Payo rezaban aquello de «no debe nada la casa $»^{51}$, lo cual permitía inver-

${ }^{48}$ A.H.U.S., Libro de Consistorios CCV, (4-IV-1759), fol. 206.

${ }^{49}$ FOLGAR DE LA CALLE, M ${ }^{a}$ del C., «La Puerta de los Carros del Convento de San Pelayo de Antealtares: Fernando de Casas y Lucas Caaveiro», en, Cuadernos de Estudios Gallegos, Tomo XXV, fasc. 100, Santiago de Compostela, 1984-85, (págs.482).

${ }^{50}$ BUJÁN, Sor Mercedes, Abadalogio Femenino del Monasterio de benedictinas de San Pelayo en Santiago de Compostela, obra inédita, (pág. 94). Vid. FOLGAR DE LA CALLE, Ma del C., «La Puerta de los Carros...», (pág. 483).

${ }^{51}$ A.S.P. Cuentas siglo XVIII, Libro de Depósito, $\mathrm{n}^{\circ} 4$, sin fol. 
...privo a que nadie se pueda asomar a los mayneles y vidrieras ni que aga corredor o solana en dicho segundo alto ${ }^{46} \ldots »$.

Lo firmaron y acordaron ambas partes, sin embargo el canónigo no cumplió su parte con lo que al menos hasta 1709 continuaron los pleitos. Nos interesa el contenido de la concordia que acabamos de transcribir porque en cierto modo nos narra cómo se iba transformando la Plaza Feijoo. Las viejas casas de pizarra fueran sustituidas por casas de cantería:

"...estaba de mala calidad y que se arruinaba en partes por ser de piedra pizarra las paredes que caiyan a dicha plazuela, y su fachada que caie a la calle que va de dicha plazuela a la Calderería ser de tabiques $^{47}$...».

Y existe una preocupación por crear una plaza hermosa, por configurar un conjunto armonioso, donde todas las viviendas guardaran normas de decoro, contribuyendo así al ornato de la ciudad. Esa plaza comienza a gozar de una estética y es dentro de este cambio donde cobra sentido que las benedictinas transformen un simple acceso al recinto en una puerta monumental que aspira a convertirse en el punto de mira de la explanada. La Plaza de Feijoo continuaba siendo un lugar de tránsito muy concurrido, un lugar no sólo tanto de ocio sino más bien para el negocio. Sin ir más lejos todavía en 1759 , y hablamos de una fecha en la que ya se ha concluido la obra de la Puerta de los Carros, en la plazuela se realizaba la venta de yerba. Ante el peligro que la actividad suponía el Ayuntamiento tomó las siguientes medidas:

«...que los hazes de paja y de hierba que diariamente se venden en esta dicha ciudad que ocupaban el paso en la plazuela de Feixó por donde bienen todas las procesiones públicas del Corpus Christiy otras que salen de la Santa Yglesia, y vienen todos los transitantes, maior

\footnotetext{
${ }^{46}$ A.C.S. Varia $1^{\text {a }}$, Serie, Tomo III, Documentos antiguos 705 , (fol. 50 v.) y A.H.U.S. Notario Pedro Vázquez, Protocolo $n^{\circ} 1994$, Concordia entre el convento de San Payo y el canonigo Don Juan Antonio Somoza, (6-IX-1707), fol. 94-95.

${ }^{47}$ A.C.S. Varia $1^{\text {a }}$, Serie, Tomo III, Documentos antiguos 705, (fol. 50).
} 
Observamos como en un principio se daban unos límites muy concretos a la obra, límites que en algún momento debieron ser cuestionados porque el lienzo que mira hacia el sur ofrece a la vista un inacabado, (Lámina 2) una dentación que señala la intención de querer continuar la obra hacia la rúa de la Conga, deseo que finalmente no se materializó. Es muy probable que ese inacabado guarde una estrechísima relación con el pleito que el Señor Canónigo Penitenciario interpuso al Monasterio. Era el 29 de Abril de 1749 cuando:

"...en este cabildo se acordó que los maestros bean esta tarde la obra del Real Monasterio de San Payo y el perjuicio que con ella puede siguirse a la casa en que bibe el Señor Pinitenciario, y según su dictamen, siendo conveniente denunpciala, disponga el señor doctoral ${ }^{54} \gg$.

Tan sólo tres días más tarde se narra como efectivamente, se había puesto embargo a la obra de San Payo. Los maestros de obras o bien no se enteraron de tal determinación, o bien hicieron caso omiso de ella, lo que les supuso, al menos a uno de ellos, la prisión:

«...avían pasado los maestros a reconozer la obra que hace el Real Monasterio de San Payo frente a la Casa del Señor Penitenciario y el perjuicio que a esta se le pueda seguir, y que según lo que habian expresado se pusiera en nombre del cabildo ante el señor Procurador Pedimiento de denunpcia a dicha obra que avia mandado poner embargo en ella, y puesto se avía innovado y prosiguido a trabajar sobre que se diera queja y se mandara prender los oficiales estando ya uno preso $^{55} \ldots{ }^{\prime} \ldots$.

A pesar de tomarse estas medidas el penitenciario al ver que el monasterio admitía la denuncia y suspendía las obras consideró oportuno que

${ }^{54}$ A.C.S., Actas Capitulares, 511, (Marzo de 1745 a Noviembre de 1750), acta del 29 de abril de 1749, fol. 260.

GARCÍA M. COLOMBAS, M.B., Las señoras de San Payo..., (pág. 280).

${ }^{55}$ A.C.S., Actas Capitulares, 511, (Marzo de 1745 a Noviembre de 1750), acta del 2 de mayo de 1749 , fol. $260 \mathrm{v}$.

"CUADERNOS DE ESTUDIOS GALLEGOS", Tomo XLVII, Fascículo 112, Santiago 2000. 


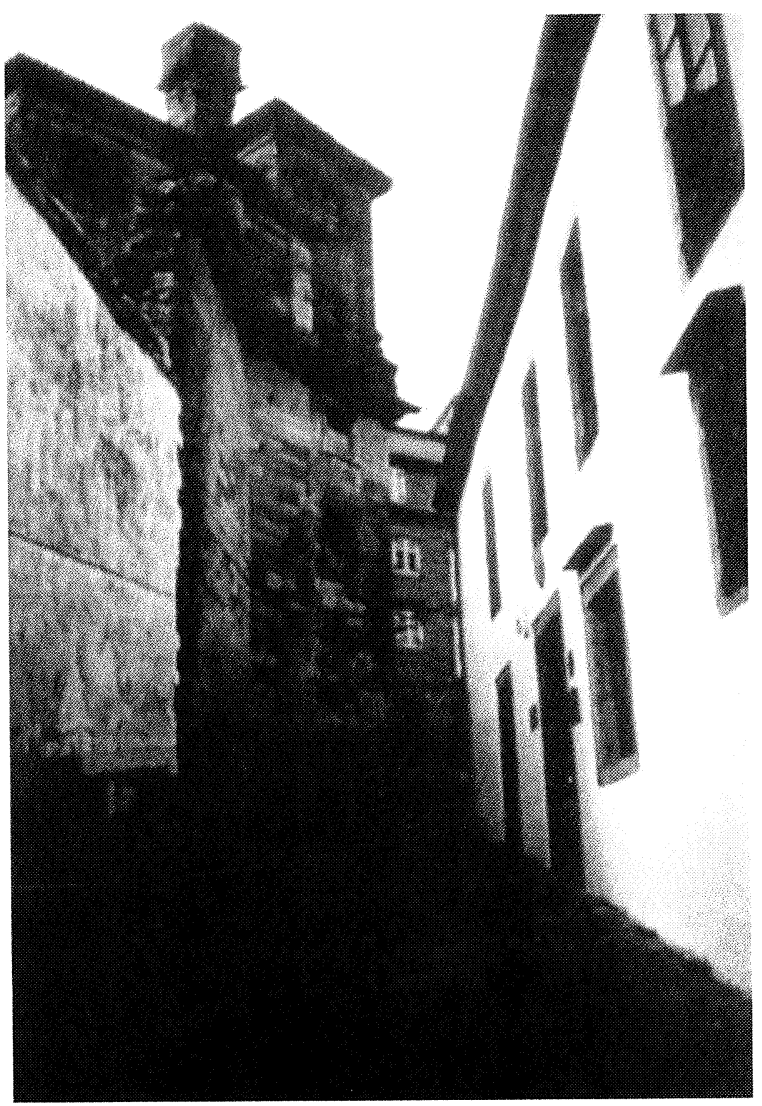

Lámina 2.- Visión del inacabado que presenta el muro hacia la rúa da Conga y casa que ocupa el lugar de la que fue del canónigo penitenciario.

cesara la criminalidad y se soltara a los $\operatorname{presos}^{56}$. Pero el embargo sobre la obra prosiguió así como el curso legal de la denuncia:

«...y comenzándose a tratar esta materia, el señor penitenciario expresó que el convento estava llano a admitir la denunpcia y subspender la obra y que si prosiguiera avía sido ygnorando que lo ejecu-

${ }^{56}$ GARCÍA M. COLOMBAS, M.B., Las señoras de San Payo..., (pág. 280).

"CUADERNOS DE ESTUdIOS GALLEGOS", Tomo XLVII, Fascículo 112, Santiago 2000. 
tado fuese denuncia y que, en nombre del Convento, pedía zesase la criminalidad y se soltasen los presos:

oydo por los señores resolvieron se suspenda lo criminal y que se prosiga el embargo puesto en dicha obra, y se siga la ynstancia y denuncia, asi quedó acordado ${ }^{57} \ldots .$.

En agosto de 1749 el pleito continuaba, de hecho encontramos noticias de él hasta abril de $1750^{58}$. Es nuestra opinión que a pesar de existir un embargo sobre la fábrica, ésta continuó su curso normal, las obras sólo debieron de paralizarse justamente hacia la zona donde habitaba el canónigo penitenciario, hacia el nacimiento de la rúa Conga, hacia ese preciso lugar donde aún hoy observamos ese dentado pétreo que nos señala que la obra está inacabada. No sabemos quien ganó el pleito, ni tan siquiera qué daño podía causar el nuevo muro a la hoy conocida como Casa de la Concha. No creemos que la demanda se deba tanto al posible incumplimiento del ancho de la calle que el ayuntamiento dispusiera ya en 1744:

«...ha de ser visto quedar de ancho de la calle desde la obbra de la esquina que ansi hizieren hasta la de la casa que se alla enffrente y en que havita el señor penitenciario de la Santa Iglesia seis varas y tres quartas por la parte que menos ${ }^{59} \ldots »$.

Creemos más bien que el problema debía de radicar en la elevada altura que los nuevos muros llevaban y que le restarían luz a la casa del canónigo. Es nuestra opinión que hacia la rúa de la Conga no se proyectó en ningún momento continuar levantando un dormitorio, sino tan sólo levantar de nuevo el viejo muro y hacerlo de cantería, y hacerlo además con

${ }^{57}$ A.C.S., Actas Capitulares, 511, (Marzo de 1745 a Noviembre de 1750), acta del 2 de mayo de 1749 , fol. $260 \mathrm{v}$.

${ }^{58}$ A.C.S., Actas Capitulares, 511, (Marzo de 1745 a Noviembre de 1750), actas del 2 de agosto de 1749, (fol. 272), del 4 de agosto de 1749, (fol. 272 v.), y del 11 de abril de 1750, (fol. 312).

En enero de 1751 hacía profesión de fe un nuevo penitenciario de nombre D. Carlos Riomol, A.C.S., Actas Capitulares, 524, libro 55, (de octubre de 1750 a septiembre de 1756) acta del 9 de enero de 1751 , fol. 11.

${ }^{59}$ A.H.U.S. Libro de Consistorios $n^{\circ} 178$, año $1748,2^{\circ}$ semestre, (20-X-1748), fol. 706 .

"CUADERNOS DE ESTUdiOS GALlEGOS", Tomo XLVII, Fascículo 112, Santiago 2000. 
una mayor altura. Las religiosas habían logrado autorización para realizar la obra, habían ganado terreno a la ciudad, pero a cambio, perdieron la posibilidad de pleitear con los vecinos que abriendo ventanas o levantando nuevos altos a sus viviendas invadieran la intimidad del monasterio. Las benedictinas tenían que elevar sus muros para salvaguardarse del mundo exterior.

En un pequeño plano realizado en 1818 (Plano V) en relación a un nuevo pleito «pro-intimidad» del convento que las monjas quieren emprender con un vecino de Fuente Sequelo ${ }^{60}$, se nos habla del dentado que el muro de San Payo tiene hacia la Rúa de la Conga, se señala con el número 5 del mapa y se cita la obra nueva como aquella comprendida entre los números 3,4 y 5 de este modo:

"Obra nueva con dentadura abierta por haver quedado suspendida en numero $5^{61} »$.

Lo cual nos indica el conocimiento por parte de las religiosas de que la obra quedó inconclusa. Es posible que el viejo muro de cierre de mampostería estuviera ruinoso, pues durante el abadiato de Isabel de Soto acaecido entre 1789 y 1793 , el Consejo del Monasterio determinó que ante la amenaza de ruina que ofrecían la fachada que mira hacia la Rúa Nueva y las dos paredes contiguas que dicen al jardín, donde se encontraban la cocina y una escalera, era necesario derribarlas y hacerlas de nuevo. ${ }^{62}$ Probablemente también ocurrió así con aquella cerca a la que ya en la década del 60 habían tenido que apuntalar tratando de fortificar ${ }^{63}$.

Todo ello confirma nuestra opinión de que en el proyecto inicial de fabricación del nuevo dormitorio no se pensara ir más allá de la Puerta de

\footnotetext{
${ }^{60}$ A.S.P., Varios 6, A-11, 8, siglo XIX, Estudio que las monjas de San Payo realizan con abogados para determinar si es factible ganar un pleito contra la casa de Brandero $n^{\circ} 11$ situada en Fuente Sequelo, doc. $n^{\circ} 1$.

${ }^{61}$ A.S.P., Varios 6, A-11, 8, siglo XIX, Papeles referentes a edificación de casas con vistas al convento, doc. $\mathrm{n}^{\circ} 2$.

${ }^{62}$ A.S.P., Libro de Depósito $\mathrm{n}^{\circ} 2$, sin fol.

GARCÍA M. COLOMBAS, M.B., Las señoras de San Payo..., (pág. 282).

BUJÁN, Sor Mercedes, Abadalogio Femenino del Monasterio... (pág. 130)

${ }^{63}$ A.S.P., Libro de Depósito n ${ }^{\circ} 6$, sin fol.

BUJÁN, Sor Mercedes, Abadalogio Femenino del Monasterio... (pág. 108).
}

"CUADERNOS DE ESTUDIOS GALLEGOS", Tomo XLVII, Fascículo 112, Santiago 2000. 
los Carros, recordemos que así es como aparece en la documentación, «desde donde termina la Vicaría hasta la Puerta de Carros $^{64}$ ». Y si en la documentación aparece citada la calle de la Conga es porque, en efecto, al tomar aquella porción de terreno que el Ayuntamiento les concedía, tenían que realizar una leve modificación en el primer tramo del muro, justamente aquel que se sitúa frente a la casa del canónigo penitenciario.

De 1749 es esta descripción de cómo era la obra que se llevaba a cabo:

«...tiene cuatro celdas en línea y cuatro altos. El primero que es el del terreno ${ }^{65}$ está todo de bóveda. El segundo tiene cuatro celdas más cortas y lo restante es zaguán y entrada de la puerta de los carros. El tercer alto tiene cuatro celdas en línea y lo mismo el cuarto alto.

Unos y otros en sus tránsitos tienen rejas de ferro y vidrieras a la calle para dar luz al dormitorio.

Las celdas tienen sus balcones (Lámina 3) bastante capaces, con sus balaustres de hierro, de forma que todas están dispuestas para vivir en ellas ${ }^{66}$.

La escalera principal de dentro que da servicio a toda la casa, con otra escalera interior que sube a los dos tramos últimos de las rejas. En estas partes se hicieron y se pusieron tragaluces grandes para dar luz suficiente a las escaleras ${ }^{67} \ldots \gg$.

Es decir un sótano para almacén (Lámina 1), una planta baja que haría las funciones de portal, zaguán, y donde además irían cuatro celdas, y cuatro celdas también para el primer piso y segundo (Lámina 4). Pero de momento no se nos habla de que se construyeran el mirador que hoy con-

${ }^{64}$ A.H.U.S. Libro de Consistorios, ${ }^{\circ} 164$, fol. 408. (VIII-1744)

${ }^{65}$ Se refiere al sótano.

${ }^{66} \mathrm{La}$ existencia de balcones en las celdas nos aporta el dato de su orientación, puesto que en un régimen de clausura sería absolutamente imposible que tales vanos se abrieran hacia la calle, es decir, los balcones tienen que abrirse hacia la zona íntima del convento, en este caso hacia la huerta, por lo tanto se orientan hacia el oeste.

${ }^{67}$ A.S.P. Libro de Depósito, ${ }^{\circ} 5$, año 1749 , sin foliar.

BUJÁN, Sor Mercedes, Abadalogio Femenino del Monasterio... (pág. 96).

GARCÍA M. COLOMBAS, M.B., Las señoras de San Payo..., (pág. 280).

FOLGAR DE LA CALLE, $\mathrm{M}^{\mathrm{a}}$ del C., «La puerta de Carros del Convento...», (pág. 483).

"CUADERNOS DE ESTUDIOS GALLEGOS", Tomo XLVII, Fascículo 112, Santiago 2000. 


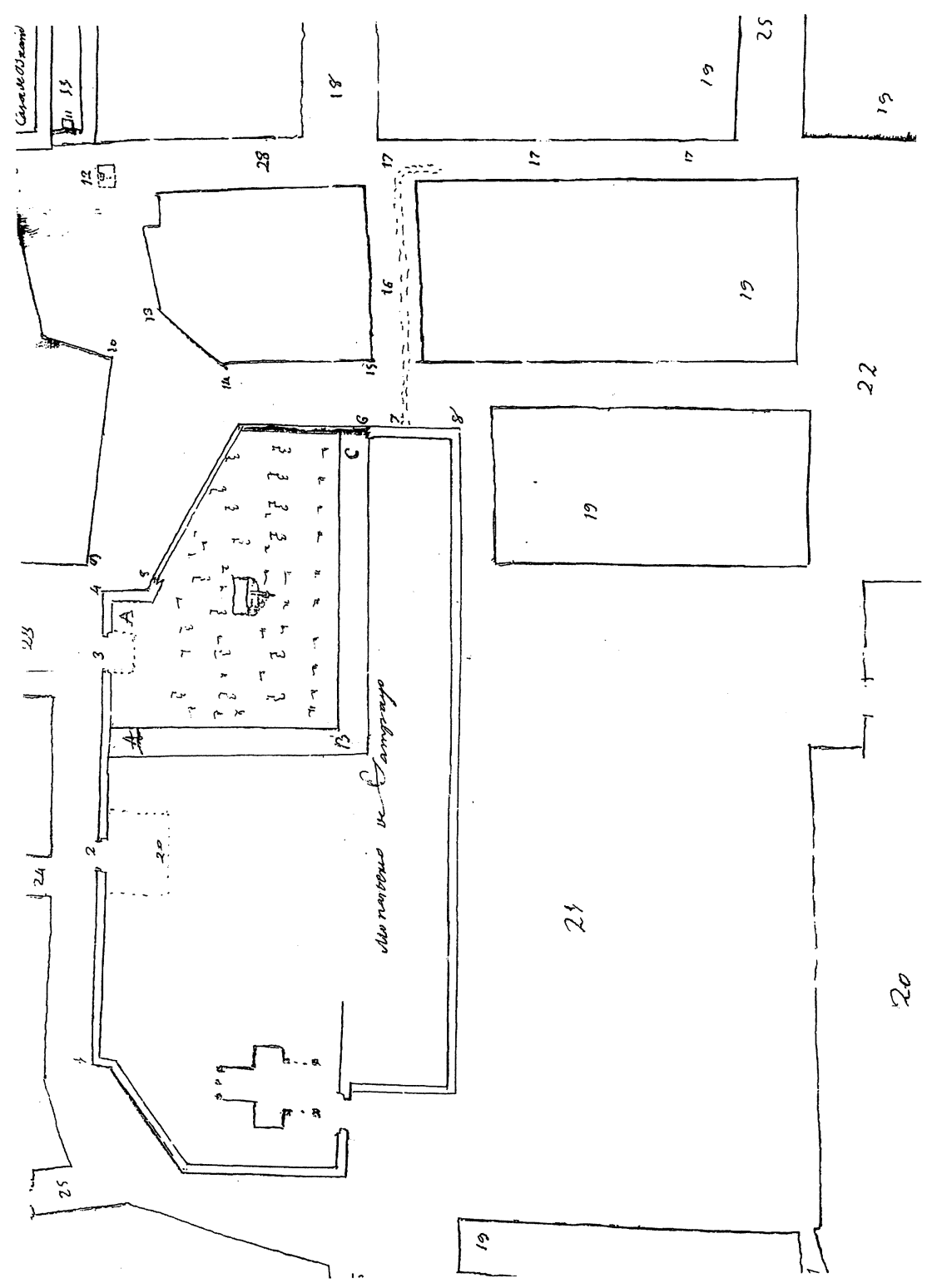

Plano V.- Plano extraído de un pleito del siglo XIX. 


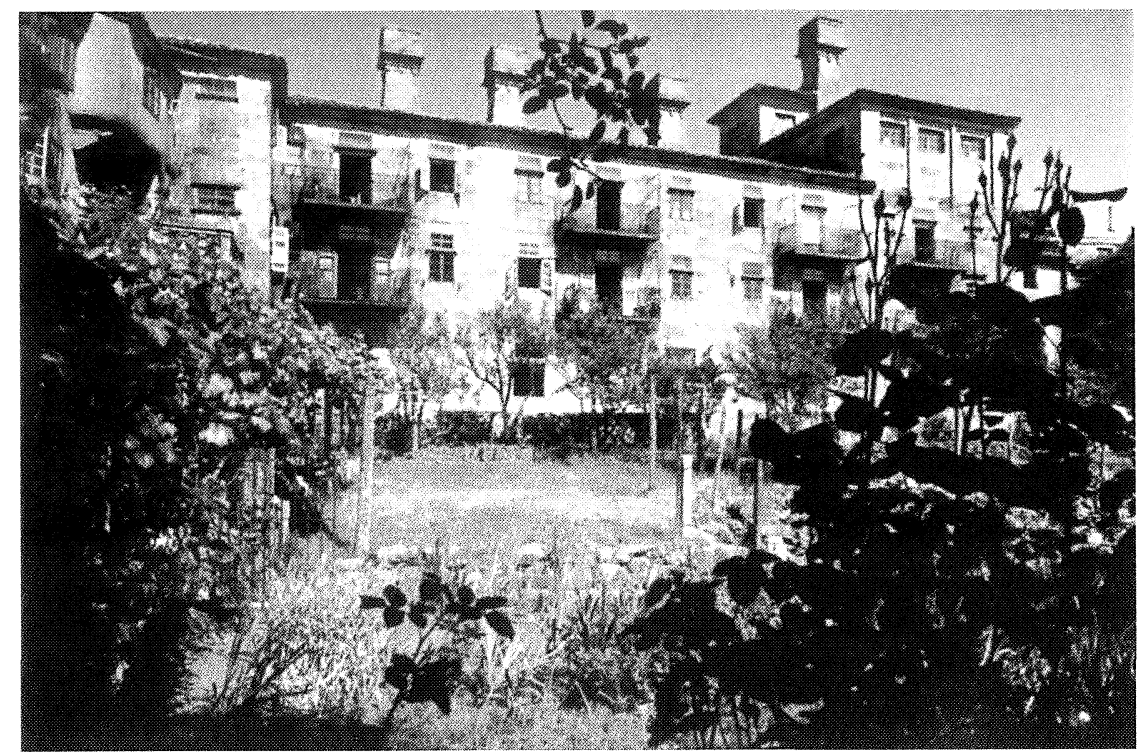

Lámina 3.- Visión del Cuarto Nuevo desde la Huerta.

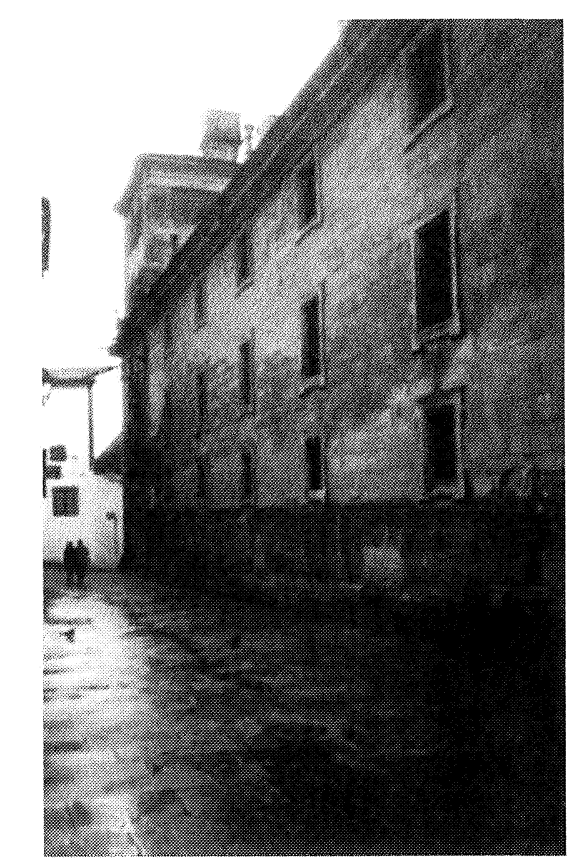

Lámina 4.- Visión de la Rúa de Tras San Payo. 


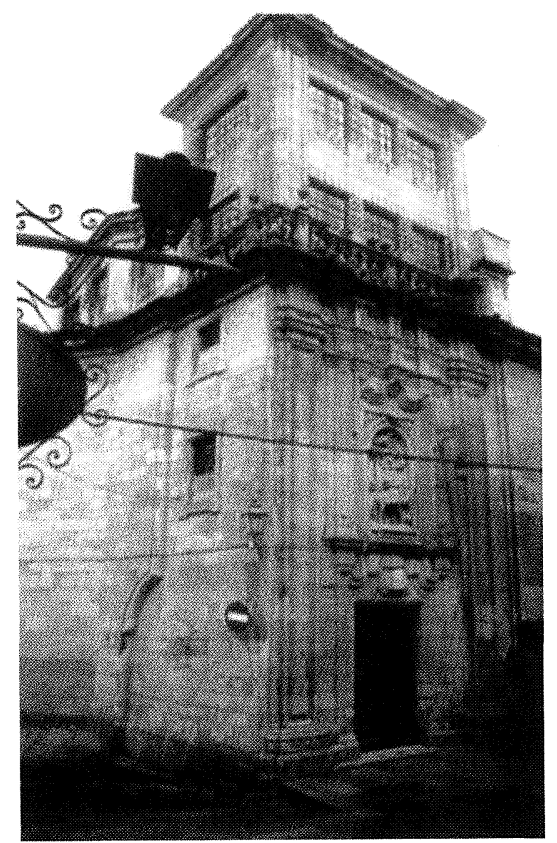

Lámina 5.- La Puerta de Carros con su mirador.

templamos sobre la portada (Lámina 5) y del conjunto escultórico que existe sobre la puerta. Sin embargo sabemos que las dos cosas estaban ya proyectadas. De este modo se recoge en el Libro de Depósito de San Payo de aquel mismo año:

«...se hicieron los pisos correspondientes y fallados, puertas y ventanas, de manera que todo queda concluido y llave en mano, a excepción de una celda y mirador, y la fachada correspondiente en que se está trabajando encima de la puerta de los carros, y queda concluyéndose la última celda a la que seguirá el mirador encima dellas, con el corredor y fachada que les corresponde, para cuyo trabajo hay mucha piedra de cantería y mampostería, y mucha parte de la madera para sus pisos, armazón, puertas y ventanas ${ }^{68} \ldots »$.

${ }^{68}$ A.S.P. Libro de Depósito, ${ }^{\circ}$ 5, año 1749, sin foliar.

BUJÁN, Sor Mercedes, Abadalogio Femenino del Monasterio... (pág. 96).

GARCÍA M. COLOMBAS, M.B., Las señoras de San Payo..., (pág. 280).

"CUADERNOS DE ESTUDIOS GALLEGOS", Tomo XLVII, Fascículo 112, Santiago 2000. 
Externamente hacia la rúa de Tras San Payo se siguió el modelo arquitectónico creado por Melchor de Velasco para la Portería. Internamente había que comunicar la obra nueva con la vicaría y portería y hacerlo de manera que no afecte a las normas de clausura de la orden benedictina:

«...para dar entrada desde el claustro principal a la obra nueva, se hicieron dos tabiques a lo largo, con lo que se cerraron las rejas, de manera que para ellas no se puede transitar no siendo por la portería de dentro y a vista de las porteras ${ }^{69} \ldots »$.

No fue hasta el abadiato de $\mathrm{D}^{\mathrm{a}}$ María Santos de Zárate (1749-1753) cuando se dio por concluida la obra:

«...se concluyó el corredor de la obra nueva y al final se hizo un mirador de dos pisos ${ }^{70} \ldots »$.

Es decir durante este cuatrienio que va del 1749 al 1753 se levantó el alto mirador que preside la fachada así como se puso fin a las obras del último piso $^{71}$. Quedaba así configurada la nueva ala del monasterio con sus diferentes niveles y sus celdas. Los tres niveles superiores poseen cada uno cuatro celdas que miran hacia la huerta, comunicadas todas ellas a un pasillo paralelo a la calle. Este pasillo está iluminado por altos ventanales, de forma que aporten luz pero que no signifiquen una comunicación con el mundo exterior.

${ }^{69}$ A.S.P. Libro de Depósito, ${ }^{\circ}$ 5, año 1749, sin foliar. BUJÁN, Sor Mercedes, Abadalogio Femenino del Monasterio... (pág. 96).

${ }^{70}$ BUJÁN, Sor Mercedes, Abadalogio Femenino del Monasterio... (pág. 98).

${ }^{71}$ Las Constituciones de la Orden establecían la obligación de continuar las obras iniciadas en los cuatrienios o abadiatos anteriores:

"Asimismo mandamos, que el Abad que entrare de nuevo en una Casa a governarla, no pueda dexar en todo su quadrienio de proseguir la obra començada por sus antecesores...» Constituciones de la Congregación de Nuestro Glorioso Padre San Benito de España e Inglaterra. Augmentadas y añadidas con las nuevas difiniciones que desde el año 1610 hasta el 1701 han sido establecidas y aprobadas en diversos capitulos (...), Impresas en Madrid a costa de la Congregación, en la oficina de la Viuda de Melchor Álvarez, año de 1706. (Consultado en el A.S.P.), capítulo 26, «Obras de los monasterios», pág. 244.

"CUADERNOS DE ESTUDIOS GALLEGOS", Tomo XLVII, Fascículo 112, Santiago 2000. 


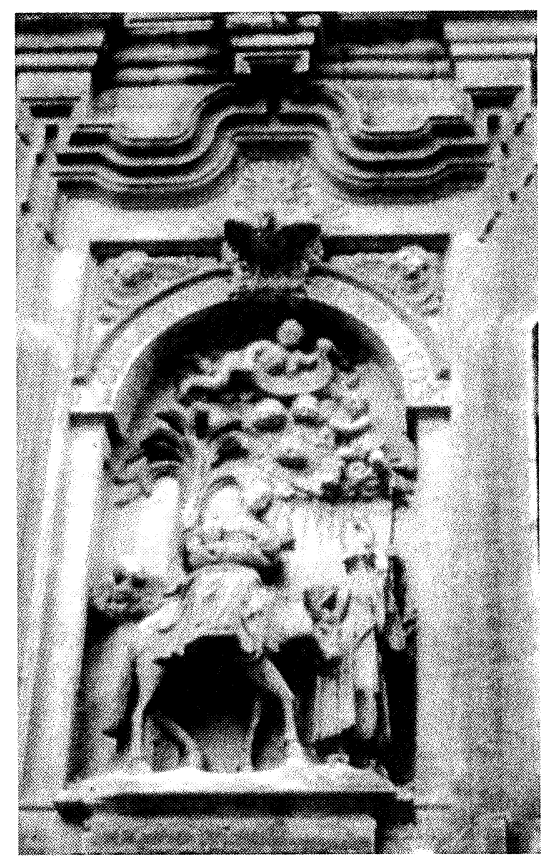

Lámina 6.- Detalle de la Portada La Huida a Egipto.

Lámina 7.- Visión de la Puerta de Carros y de la Plazuela de Feijoo.

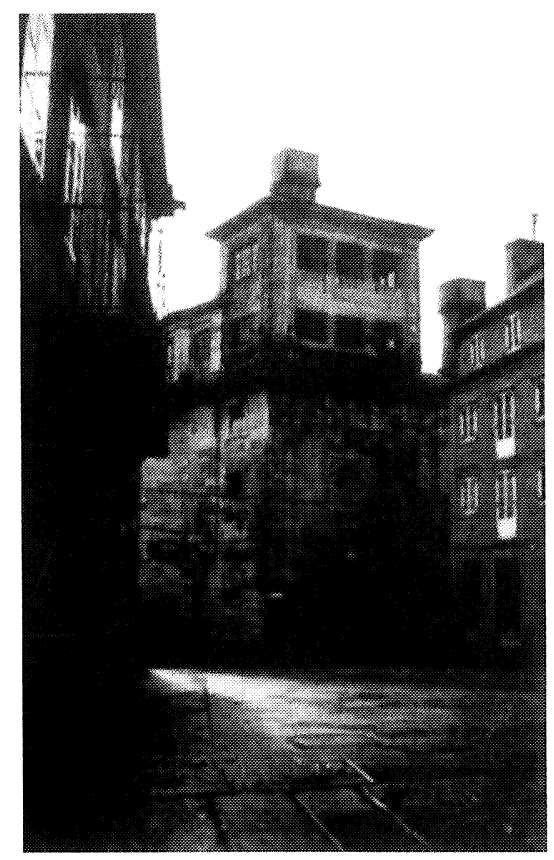




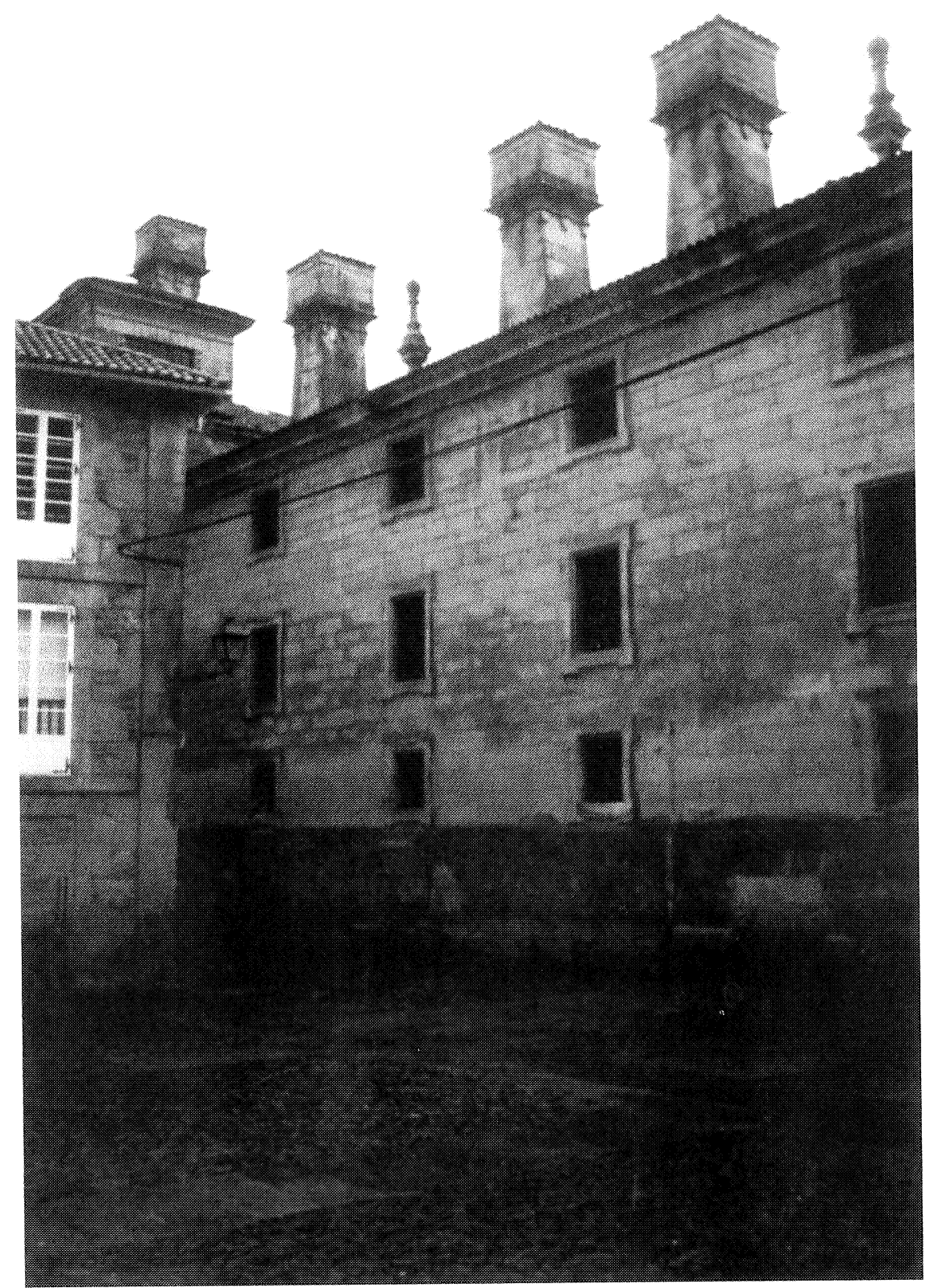

Lámina 8.- Chimeneas. 


\section{A MODO DE CONCLUSIÓN}

La Puerta de los Carros cuenta con una plasticidad, un movimiento de líneas y un sentido escenográfico modélicos. Estamos hablando de una de las últimas y más delicadas creaciones de la cultura barroca en Galicia, hablamos de un delicioso marco para una huida a Egipto, para un pasaje de peregrinación que engalana un rincón de la ciudad jacobea. (Lámina 6).

La elección de este tema no fue para nada arbitraria, primero porque nos habla de la función aquel acceso, por allí entraban los burros, los animales de carga, los carros... Iconograficamente «la borriquita» se adapta al sentido «viajero» de los carreteros que traían las cargas de cereales desde los prioratos y anexos del monasterio, pero además, en Compostela nunca podemos olvidar la esencia peregrina que irradia la Catedral, ese sentido de peregrinación está patente en la Seo y en las calles.

Un último aporte es el que más nos aproxima a esta advocación como una de las devociones que ya existía en el Monasterio, para demostrarlo no hay más que entrar en la iglesia conventual y observar el retablo del crucero que hace frente al relicario de Casas. Allí encontramos este mismo tema realizado en la primera mitad del XVIII.

También se repite el escudo benedictino que aparece en las pechinas de la iglesia, en la fachada de la Portería y nuevamente en las metopas de la Puerta de Carros, si bien en este último caso su presencia es menos «poderosa» que en los dos anteriormente citados.

Contemplando la portada desde la Calderería nos sentimos aprisionados y en parte sometidos por la fuerte presencia pétrea del torreón-mirador, ¿acaso hay otro modo más eficaz de exteriorizar desde los recios muros de una clausura, la importancia de sus moradoras? Hablamos de un monasterio poderoso, con anexos, con prioratos, con una importante vida económica y con unas nobiliarias habitantes. Hablamos del único Monasterio de la Ciudad que compitió con sus muros con la propia Catedral, sucedió en el siglo XVII cuando levantó el lienzo mural que mira a la Quintana, cuya sobria pero monumental presencia, obligó al cabildo catedralicio a reformar la vetusta y caótica cabecera catedralicia.

San Payo es un complejo conjunto, su iglesia, o cada una de sus portadas son el testimonio preciso de un tiempo, de una cronología determinada. En cada una de esas fechas, en cada uno de esos períodos, el monasterio quiso «ser» hacia el exterior, diferentes fachadas, diferentes rostros para una misma imagen de poder, el poder que nunca ha querido perder.

"CUADERNOS DE ESTUDIOS GALLEGOS", Tomo XLVII, Fascículo 112, Santiago 2000. 
En el caso que nos ocupa, al hablar de la Puerta de Carros hablamos, en suma, de una obra del urbanismo barroco, porque esta portada quiere engalanar una plazuela, quiere adornarla, quiere deja notar su pétrea presencia, quiere dominarla desde su monumental e impresionante torreón.

Los arquitectos supieron sacar partido del desnivel existente entre la calle de la Calderería, que transcurre a mayor altura por el este de la plazuela de Feijoo, y el propio monasterio, en la zona oeste de la plaza, paralelo a la calle pero a menor nivel. De esta diferencia de alturas se aprovecharon los maestros arquitectos, por ello y para ello solicitaron aquel pedazo de vía pública que había señalado Fernando de Casas sobre el pequeño plano al que ya hemos hecho mención, porque de este modo lograban un perfecto ángulo recto entre la portada y el ojo inquieto de peregrinos y transeúntes que desde la Calderería dirigiera su mirada hacia la plaza (Lamina 7). Es desde este sentido como la Puerta de los Carros se convierte en el testimonio de la presencia y del poder del Monasterio de San Payo.

Otro aspecto urbano digno de mención son las chimeneas, (Lámina 8) porque en ellas se encierra otra particularidad del arte barroco. Es cierto que el urbanismo santiagués del barroco busca cerrar sus calles con lienzos murales que desconcierten al espectador, pero también lo es que nuestro barroco tiene un especial interés por las partes altas ${ }^{72}$, y es en esas alturas donde se colocan las cuatro volumétricas chimeneas, una sobre el mirador y las tres restantes sobre el tejado del dormitorio. Tamaño desorbitado y perspectiva inquietante, son las características fundamentales de estos «escapes de humos» que han sido estudiados estilísticamente por Folgar de la Calle.

Al concluir esta obra, el Monasterio de Antealtares cesó su febril y secular actividad constructiva, manteniendo la llama vibrante de su espiritualidad, encerrada en ese berroqueño estuche que ennoblece el corazón de la Compostela monumental. A partir de este momento llegaría la crisis a este cenobio; arcas vacías, inestabilidad interna y externa impidieron a las religiosas continuar ya no incrementando, sino tan sólo manteniendo un poder que inevitablemente huyó para siempre.

${ }^{72}$ BONET CORREA, A., «El urbanismo barroco y la Plaza del Obradoiro de Santiago de Compostela», en Archivo Español de Arte, 1959.

"CUADERNOS DE ESTUDIOS GALLEGOS", Tomo XLVII, Fascículo 112, Santiago 2000. 